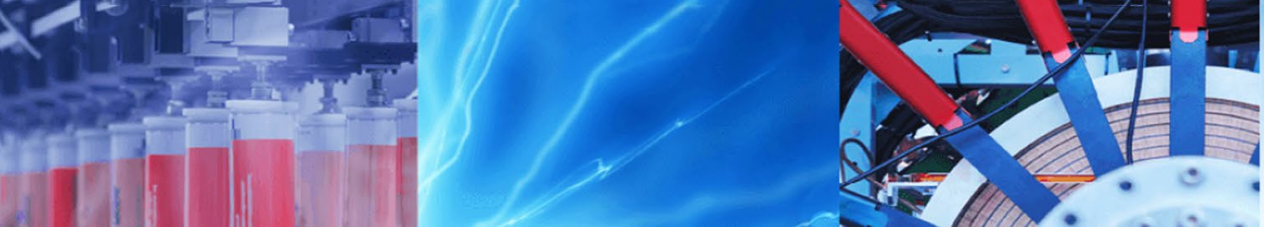

Research Article

\title{
Thermodynamic properties and contact angles of CTAB and SDS in acetone-water mixtures at different temperatures
}

\author{
Yubaraj Ghimire $^{1} \cdot$ Sharmila Amatya ${ }^{1} \cdot$ Sujit Kumar Shah ${ }^{1}$ (I) $\cdot$ Ajaya Bhattarai ${ }^{1}$ (I)
}

Received: 7 April 2020 / Accepted: 10 June 2020 / Published online: 27 June 2020

(c) Springer Nature Switzerland AG 2020

\begin{abstract}
The thermodynamic properties of sodium dodecyl sulfate (SDS) and cetyltrimethylammonium bromide (CTAB) in neat water and acetone-water mixtures were studied by measuring the conductivity at 298.15, 308.15, 318.15 and $323.15 \mathrm{~K}$. The critical micelle concentration (CMC), degree of ionization (a), standard Gibbs free energy of micellization $\left(\Delta G_{\mathrm{m}}^{\circ}\right)$, standard entropy of micellization $\left(\Delta S_{\mathrm{m}}^{\circ}\right)$, standard heat of micellization $\left(\Delta H_{\mathrm{m}}^{\circ}\right)$, the heat capacity of micellization $\left(\Delta_{\mathrm{m}} C_{\mathrm{p}}^{\circ}\right)$ and free energy of transfer $\left(\Delta G_{\text {trans }}^{\circ}\right)$ were evaluated from conductivity data. The contact angles (CAs) were measured using a drop shape analyzer (DSA-25E). The correlation of $\Delta G_{\mathrm{m}}^{\circ}$ with solvent parameters and the solvophobic parameter was explored.
\end{abstract}

Keywords Sodium dodecyl sulfate $\cdot$ Cetyltrimethylammonium bromide $\cdot$ Acetone-water · Conductivity · Contact angle

\section{Introduction}

Surfactants are defined as the class of compounds tending to form aggregates called micelles [1]. CMC is a concentration at which micelle is formed. Micelle formation of surfactants is caused by hydrophobic interactions of hydrocarbon tails with water balanced by electrostatic repulsions between the surfactant head groups [2]. CMC, $a$ and $\Delta G_{m}^{\circ}$ depend on the nature of the hydrophobic tail, the hydrophilic head group and the counter ion species [3]. There are few studies on micelle arrangement in a water-acetone system. Miyagishi [4] examined the impact of organic additives such as alcohols, urea, dioxane, acetone and formamide on the micellization of an aqueous solution of dodecyl ammonium halides utilizing a conductivity technique and an emf cell. Moreover, Miyagishi investigated the effect of acetone, 1-propanol and urea on the micellization of dodecylammonium chloride and iodide [5] and the effect of acetone and 1-propanol on the micellization of a series of alkylammonium chlorides $\left(\mathrm{C}_{12}-\mathrm{C}_{18}\right)$ [6]. Miyagishi calculated the CMC, $a$, the effective coefficient of electrical energy and thermodynamic parameters. The investigation shows that organic additives show remarkable changes in the thermodynamic properties of the surfactant solution.

Treiner and Besnerais [7] calculated $\Delta G_{\text {trans }}^{\circ}$ of SDS and DTAB from neat water to water-acetone mixtures by the method of vapor weight estimations and have additionally found out $a$ and apparent charge of micelles of similar surfactants in water-acetone and water-n-propanol solutions by the method of conductivity.

lonescu and Favere investigated the effect of acetone on the formation of micelle of CTAB in aqueous medium at $25^{\circ} \mathrm{C}$ and $40{ }^{\circ} \mathrm{C}$ by means of surface tension measurements. In the absence of acetone, they calculated the value of $\Delta G_{\mathrm{m}}^{\circ}$ is $-17.3 \mathrm{~kJ} / \mathrm{mol}$ with CMC $0.92 \mathrm{mM}$ at $25^{\circ} \mathrm{C}$. But at $0.0755 \mathrm{~mol}$ fraction acetone, the value of $\Delta G_{\mathrm{m}}^{\circ}$ is $-14.7 \mathrm{~kJ} / \mathrm{mol}$ with CMC $2.20 \mathrm{mM}$ at the same temperature. At higher mole fractions of acetone viz. 0.0949 and 0.140 formation of micelles have not been reported [8].

Yadav and Bhattarai [9] investigated the effect of ethanol on the micellization of SDS in an aqueous medium by conductivity measurement and reported that the

Ajaya Bhattarai, bkajaya@yahoo.com | 'Department of Chemistry, M.M.A.M.C., Tribhuvan University, Biratnagar, Province No. 1, Nepal. 
conductivity of SDS in ethanol-water is inversely proportional to the volume of ethanol because of the decrease in the dielectric constant. Bhattarai et al. [10] worked with SDS in the presence of CTAB in neat water and three different methanol-water mixtures $(0.1,0.2$ and 0.3 volume fractions methanol) at 298.15, 308.15, 318.15 and $323.15 \mathrm{~K}$ and observed that value of density of SDS in the presence of $C T A B$ in neat water and methanol-water mixture is higher than the density of SDS in the presence of water and methanol-water mixture. Cookey et al. [11] observed CMC of SDS increases with temperature at a given composition. At 0.1 mole fraction of ethylene glycol, the CMC increased from $5.7 \mathrm{mM}$ to $6.7 \mathrm{mM}$ as the temperature increased from 303.15 to $313.15 \mathrm{~K}$ after measuring by a conductivity meter (model DDS 307A). Malliaris and Binana [12] measured the conductance of SDS in acetone-water mixtures and found that initially, CMC decreased on adding acetone; maximum depression was seen at $1.14 \%$ of acetone and then increased until finally micellar formation was inhibited at acetone concentrations above $25 \%$. From the graph, it was observed that CMC decreased above $30 \%$ acetone concentration $(\mathrm{v} / \mathrm{v})$.

Here, we studied the effect of acetone and temperature on the micellization of CTAB and SDS by conductivity measurement and calculated the CMC, $a, \Delta G_{m^{\prime}}^{\circ} \Delta S_{m^{\prime}}^{\circ} \Delta H_{m^{\prime}}^{\circ}$ $\Delta_{\mathrm{m}} C_{\mathrm{p}}^{\circ}$ and $\Delta G_{\text {trans }}^{\circ}$. The effect of acetone on micellization behavior was also observed by contact angle measurement. The correlation of $\Delta G_{\mathrm{m}}^{\circ}$ with the solvent parameters and the solvophobic parameter is included.

\section{Experimental section}

\subsection{Materials}

In this work, SDS of molecular weight $288.372 \mathrm{~g} / \mathrm{mol}$ and CTAB of molecular weight $364.45 \mathrm{~g} / \mathrm{mol}$ were purchased from Loba Chemical Private Limited, India. Acetone was obtained from Fischer Scientific India Pvt. Ltd. The assay percentage range was $99 \%$ and was a certified reagent grade solvent. Surfactants were dried for $1 \mathrm{~h}$. Triply distilled water with a specific conductance of $<0.6 \mu \mathrm{S} / \mathrm{cm}$ at $298.15 \mathrm{~K}$ was used. Solutions were prepared in neat water and 0.10 to 0.40 volume fraction of acetone-water. The concentration range of the solutions was $\sim 0.01 \mathrm{~mol} \mathrm{~L}^{-1}$ at $298.15,308.15,318.15$ and $323.15 \mathrm{~K}$.

\subsection{Electrical conductivity measurements}

Conductance measurements were done on a Pye-Unicam PW 9509 conductivity meter at a frequency of $2000 \mathrm{~Hz}$ utilizing a dip - type cell with a cell constant of $1.15 \mathrm{~cm}^{-1}$ and with an uncertainty of $0.01 \%$. The cell was adjusted utilizing aqueous $\mathrm{KCl}$ solution [13]. To maintain different temperatures, a digital water bath purchased from India was used.

\subsection{Contact angles measurements}

Contact angles were measured using Kruss-DSA25E, Germany. The contact angles of CTAB and SDS solutions of different concentrations in the acetone-water mixture were determined by the sessile drop method over the borosilicate glass surface and aluminum surface respectively. Different concentrations of CTAB and SDS (above and below $\mathrm{CMC}$ ) were prepared and for each concentration, the contact angles were measured using DSA software.

\section{Results and discussion}

\subsection{Specific conductance of the SDS and CTAB solutions}

The specific conductance study is one of the useful methods to understand the physicochemical properties of the solutions of surfactants. The conductometric plots of SDS and CTAB in water and acetone-water mixtures at 298.15, 308.15, 318.15 and $323.15 \mathrm{~K}$ are presented in Figs. 1, 2 and 3 (for CTAB) and in Figs. 4, 5 and 6 (for SDS) respectively. The specific conductance increases with an increase in concentration with a certain inclination. The meeting point of the two straight lines is a CMC. The premicellar and postmicellar slopes were used to calculate $a$.

From Figs. 1, 2, 3, 4, 5 and 6, it is apparent that the specific conductance shows a sharp increase with concentration, which is due to an increase in the number of ions by unit volume of the solution. The increase in specific conductance with temperature is observed and it is due to the decrease in the viscosity of the solution; that there is an increase in the speed of the ions and hence the increase in a.

Table 1 displays the values of premicellar $\left(\mathrm{S}_{1}\right)$ and postmicellar $\left(\mathrm{S}_{2}\right)$ slopes drawn from the graphs of specific conductance with the concentration of CTAB and SDS solutions of acetone-water mixtures. It is observed from the data in Table 1 that there is a decrease in the slopes of the $S_{1}$ region compared to the $S_{2}$ region with the increase in acetone.

The increase in a upon the addition of acetone may be due to a diminished polarity, which rises the repulsion between ionic head groups and diminishes micelle stability, which in turn also decreases the corresponding charge density.

The rising temperature may rise the steric volume of the head in the micelle and hence $a$ is affected [14]. Two forces as coulombic and thermal are responsible 

ency of the conductance for CTAB in neat water at $298.15 \mathrm{~K}$ (open triangle), $308.15 \mathrm{~K}$ (open square), $318.15 \mathrm{~K}$ (closed square)
Fig. 1 Concentration dependtriangle) and $323.15 \mathrm{~K}$ (closed

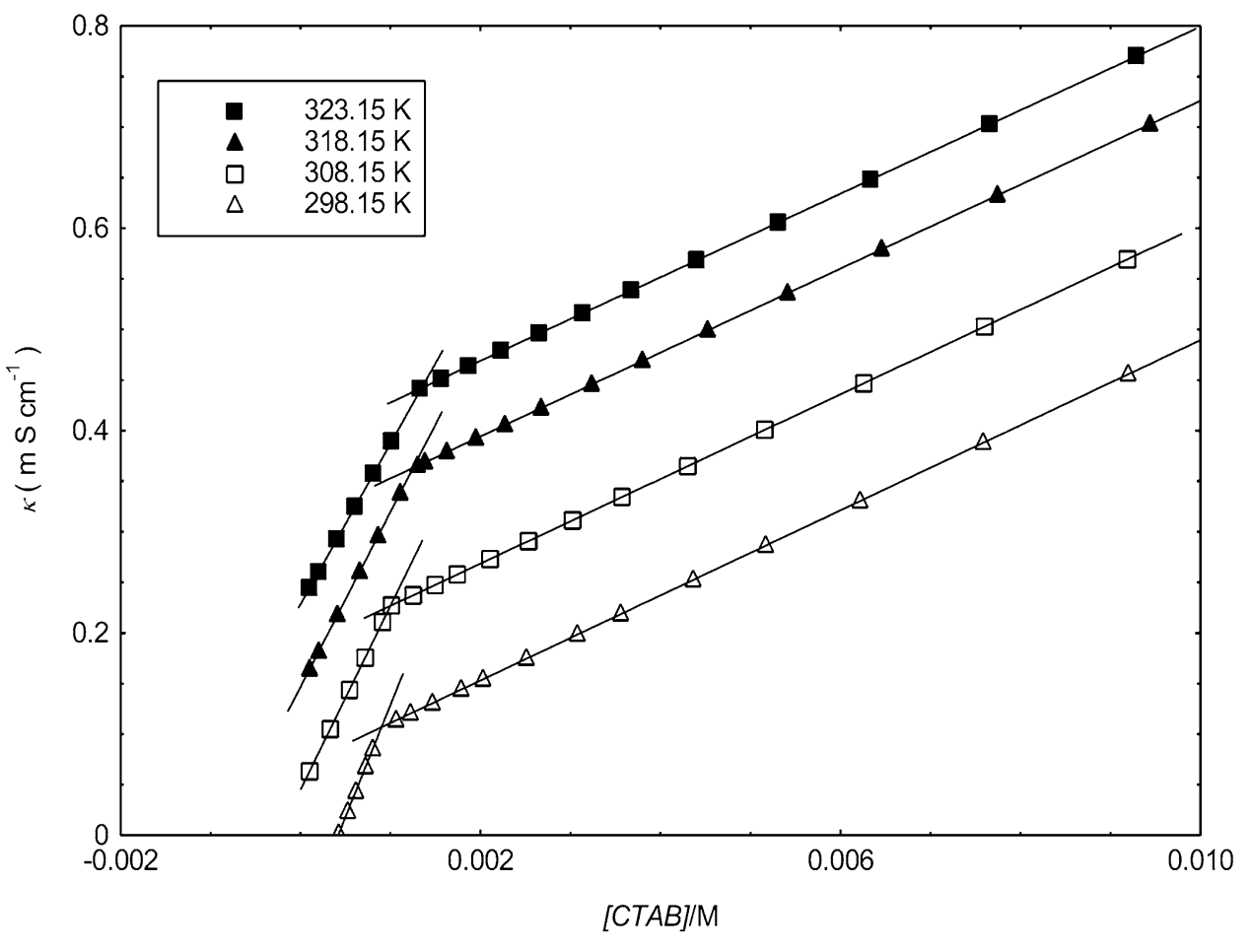

Fig. 2 Concentration dependency of the conductance for CTAB in 0.10 volume fraction of acetone at $298.15 \mathrm{~K}$ (open triangle), $308.15 \mathrm{~K}$ (open square), $318.15 \mathrm{~K}$ (closed triangle) and $323.15 \mathrm{~K}$ (closed square)

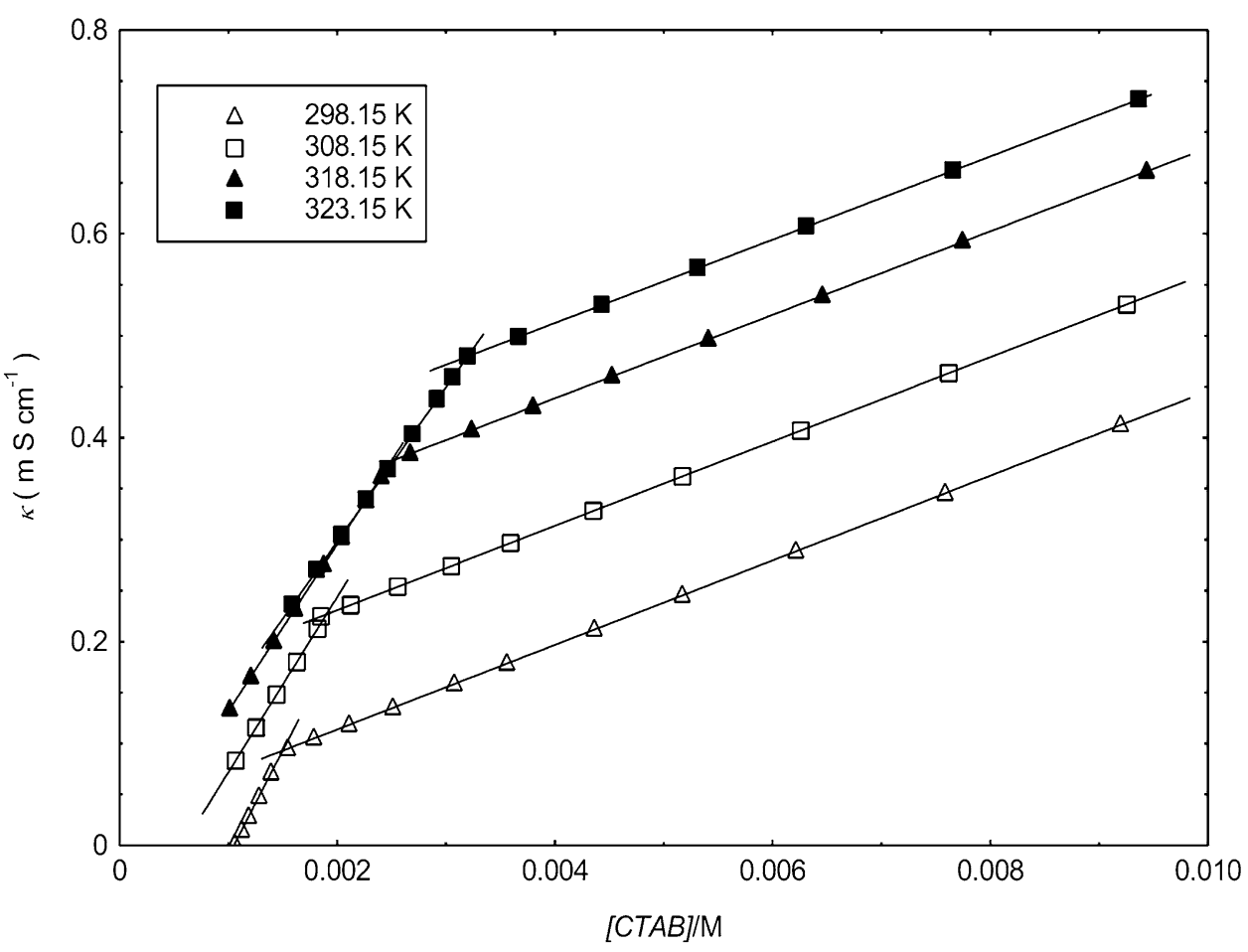

for the increase in a [15]. The former force is assigned to the attraction of the counter ions to the polar head and the second force is temperature-dependent. When the temperature is increased, the thermal force prevails over the coulombic force and the degree of ionization increases. 
Fig. 3 Concentration dependency of the conductance for CTAB in 0.20 volume fraction of acetone at $298.15 \mathrm{~K}$ (open triangle), $308.15 \mathrm{~K}$ (open square), $318.15 \mathrm{~K}$ (closed triangle) and $323.15 \mathrm{~K}$ (closed square)

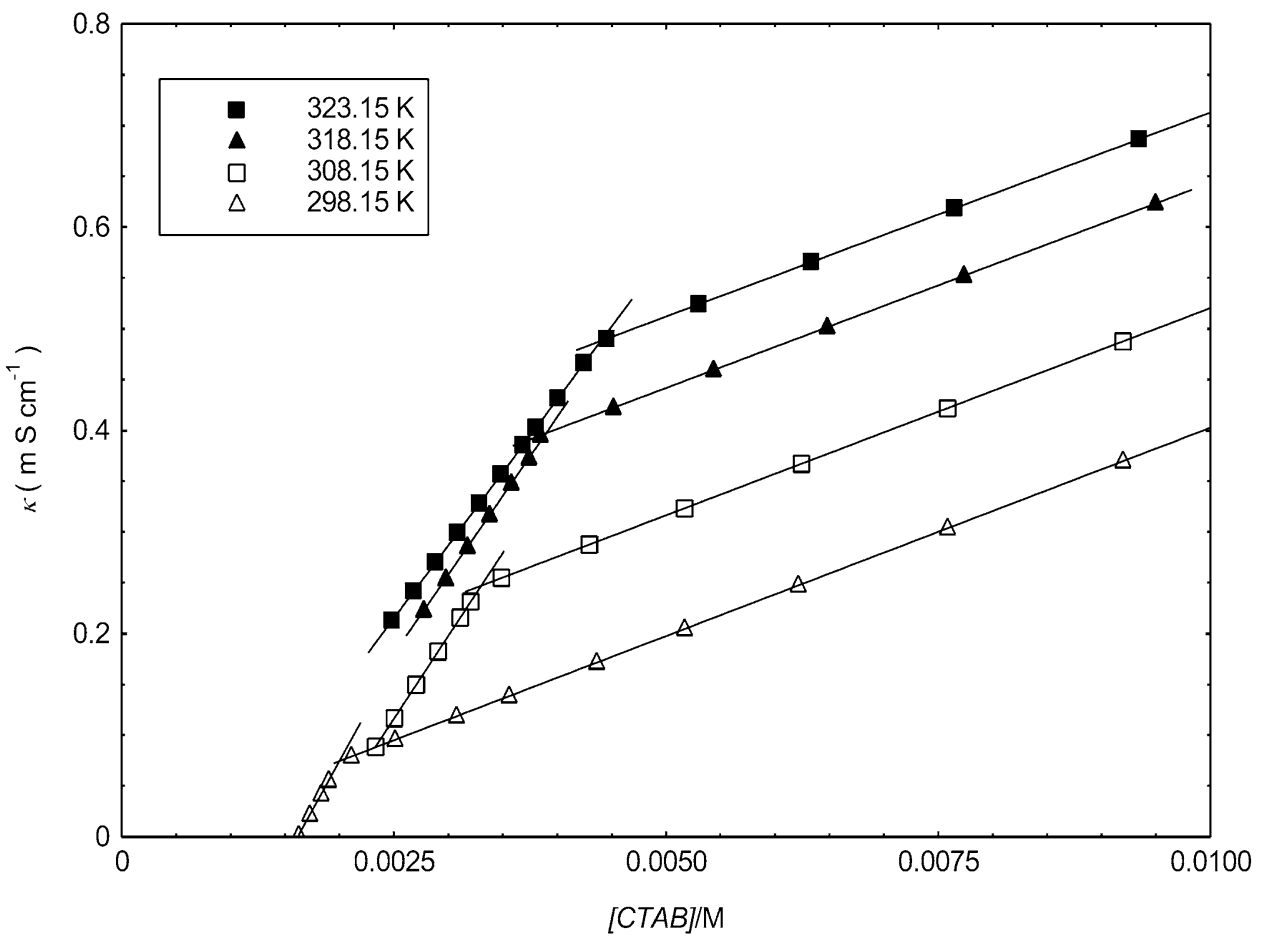

Fig. 4 Concentration dependency of the conductance for SDS in neat water at 298.15, $308.15,318.15$ and $323.15 \mathrm{~K}$

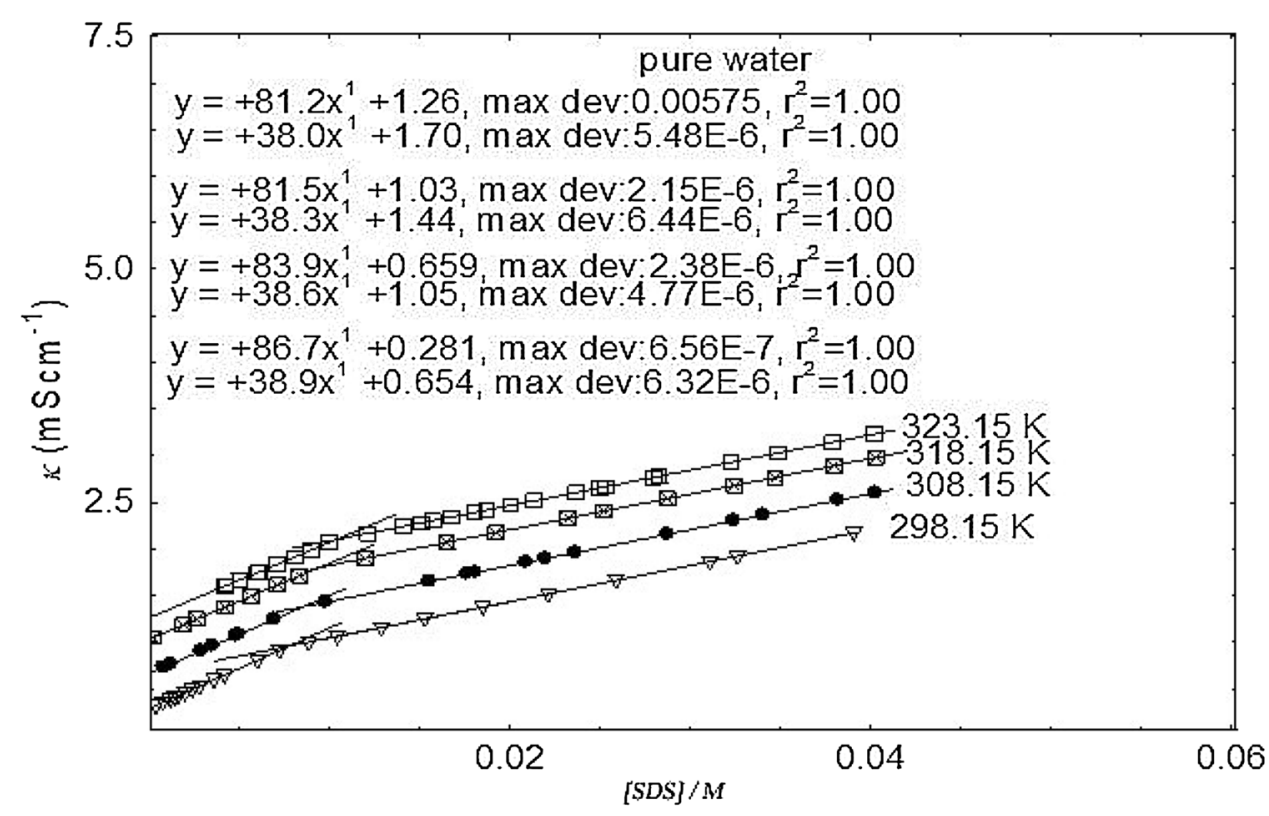

\subsection{Thermodynamics of micellization}

After finding the value of $\mathrm{cmc}$, we can ascertain significant thermodynamic parameters as $\Delta G_{\mathrm{m}}^{\circ}$ can be calculated from a pseudo-phase separation model $[13,16]$ :

$\Delta G_{\mathrm{m}}^{\mathrm{o}}=(2-\alpha) \mathrm{RT} \ln X_{\mathrm{cmc}}$

The standard heat of micelle formation, $\Delta H_{\mathrm{m}}^{\circ}$, can be evaluated from the Gibbs-Helmholtz equation [17]:
$\Delta H_{\mathrm{m}}^{\mathrm{o}}=-\mathrm{RT}^{2}(2-\alpha)\left[\partial \ln X_{\mathrm{cmc}} / \partial \mathrm{T}\right]_{\mathrm{P}}$

The term $\left[\partial \ln X_{\mathrm{cmc}} / \partial T\right]_{P}$ is evaluated by fitting the graph of $\ln X_{\mathrm{cmc}}$ versus temperature and using the corresponding temperature derivative. $\Delta S_{\mathrm{m}}^{\circ}$ can be calculated using the following equation:

$\mathrm{T} \Delta S_{\mathrm{m}}^{\circ}=\Delta H_{\mathrm{m}}^{\circ}-\Delta G_{\mathrm{m}}^{\circ}$ 
Fig. 5 Concentration dependency of the conductance for SDS in 0.10 volume fraction of acetone at $298.15,308.15$, 318.15 and $323.15 \mathrm{~K}$
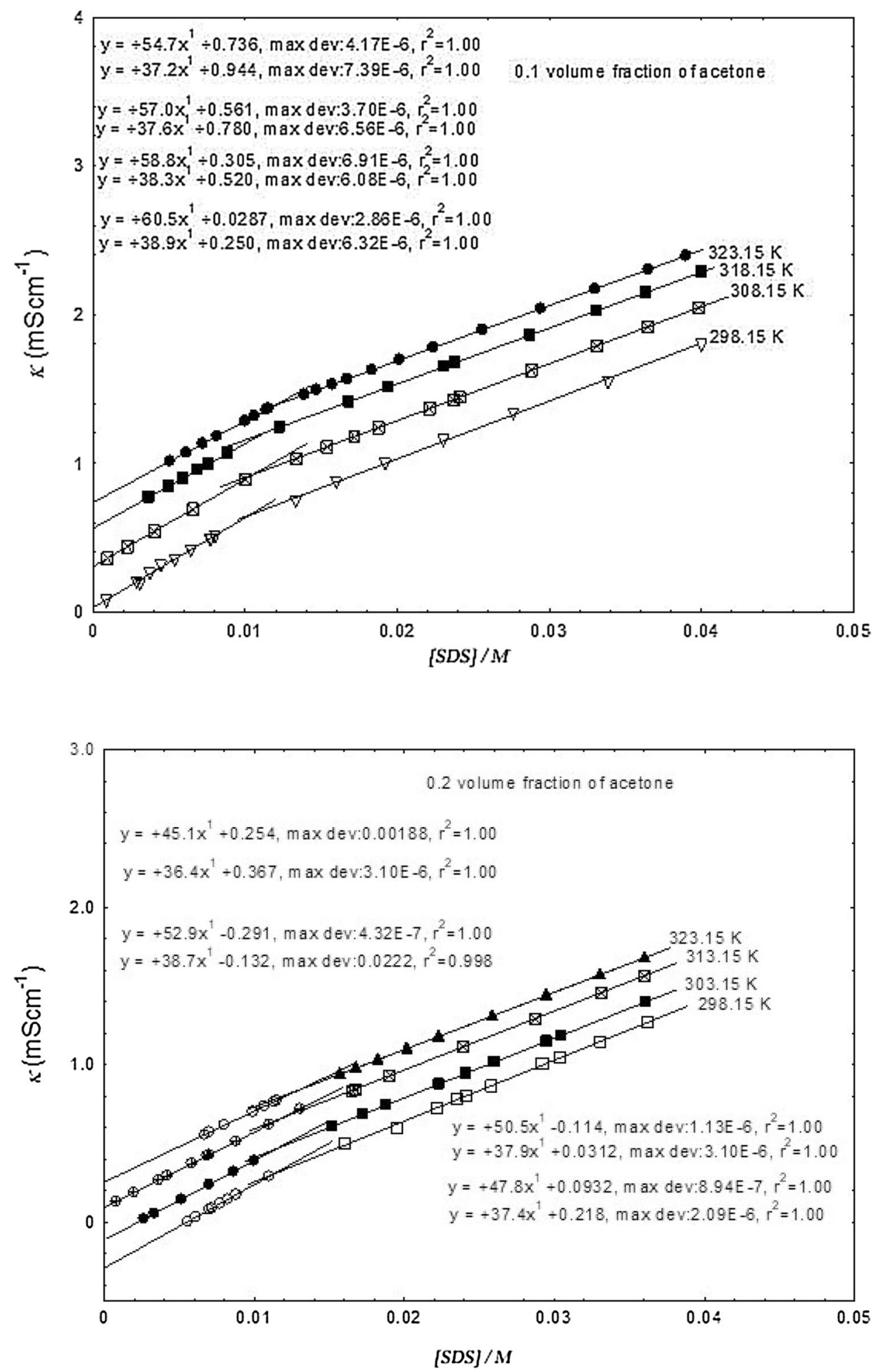

Fig. 6 Concentration dependency of the conductance for SDS in 0.20 volume fraction of acetone at 298.15, 308.15, 318.15 and $323.15 \mathrm{~K}$ where $a=$ degree of dissociation, $X_{\mathrm{cmc}}=$ mole fraction of surfactant at $C M C, R=$ universal gas constant and $T=$ absolute temperature.

Also, the effect of acetone on the aggregation process can be studied using $\Delta G_{\text {trans }}^{\circ}$, which is defined by [16]:
$\Delta G_{\text {trans }}^{\mathrm{o}}=\left(\Delta G_{\mathrm{m}}^{\mathrm{o}}\right)_{\text {acetone+water }}-\left(\Delta G_{\mathrm{m}}^{\mathrm{o}}\right)_{\text {water }}$

A linear variation observed between $\Delta H_{\mathrm{m}}^{\circ}$ and $\Delta \mathrm{S}_{\mathrm{m}}^{\circ}$ is calculated with the help of the relation (5). 
Table $1 \mathrm{~S}_{1}$ and $\mathrm{S}_{2}$ for $\mathrm{CTAB}$ and SDS obtained from conductance measurements in neat water and acetone-water mixtures containing $0.0,0.10$ and 0.20 volume fractions of acetone at $298.15,308.15$, 318.15 and $323.15 \mathrm{~K}$

\begin{tabular}{llll}
\hline Temperature $(\mathrm{K})$ & Vol. fraction of acetone & $\mathrm{CTAB}$ & $\mathrm{SDS}$ \\
& & $\mathrm{S}_{1}, \mathrm{~S}_{2}\left(\mathrm{mS} \mathrm{cm}^{-1} \mathrm{M}^{-1}\right)$ & $\mathrm{S}_{1}, \mathrm{~S}_{2}\left(\mathrm{mS} \mathrm{cm}^{-1} \mathrm{M}^{-1}\right)$ \\
\hline 298.15 & 0 & $222,42.1$ & $86.7,38.9$ \\
& 0.1 & $208,41.5$ & $60.5,38.8$ \\
308.15 & 0.2 & $195,41.0$ & $52.9,38.6$ \\
& 0 & $182,41.8$ & $83.9,38.6$ \\
318.15 & 0.1 & $172,41.3$ & $58.8,38.3$ \\
& 0.2 & $163,40.8$ & $50.5,37.5$ \\
& 0 & $173,41.5$ & $81.5,33.3$ \\
323.15 & 0.1 & $164,41.0$ & $57.0,37.6$ \\
& 0.2 & $155,40.4$ & $47.8,37.4$ \\
& 0 & $159,41.3$ & $79.1,38.0$ \\
& 0.1 & $152,40.9$ & $54.9,37.2$ \\
& 0.2 & $144,40.2$ & $46.1,36.4$ \\
\hline
\end{tabular}

$\Delta S_{\mathrm{m}}^{\circ}=\frac{1}{\mathrm{~T}_{\mathrm{c}}} \Delta H_{\mathrm{m}}^{\mathrm{o}}+\sigma$

where $\frac{1}{T_{c}}$ is the slope and $\sigma$ is the intercept of a linear plot. $\mathrm{T}_{c}$ refers to the solvation part of micellization, the $\sigma$ measures solute-solvent interaction. The temperature dependence of the hydrophobic impact communicated as $\Delta_{\mathrm{m}} C_{\mathrm{p}}^{\circ}$ and determined from the slope of $\Delta H_{\mathrm{m}}^{\circ}$ versus temperature graph is noted as follows:

$\Delta_{\mathrm{m}} C_{\mathrm{P}}^{\circ}=\frac{\partial \Delta H_{\mathrm{m}}^{\circ}}{\partial \mathrm{T}}$

The thermodynamic properties of micellization, such as $\Delta G_{\mathrm{m}}^{\circ}, \Delta H_{\mathrm{m}}^{\circ}, \Delta S_{\mathrm{m}}^{\circ}$ and $\Delta G_{\text {trans }}^{\circ}$ are shown in Tables 2 and 3 for CTAB and SDS respectively in water as well as acetone-water mixtures at 298.15, 308.15, 318.15 and $323.15 \mathrm{~K}$.
It is evident from Tables 2 and 3 that the free energy and enthalpy of micelle formation are negative in all cases and that the free energy becomes less negative as the acetone content in the mixture increases, indicating that the micelle formation becomes less spontaneous at higher acetone content. This behavior suggests that micellization becomes less favorable at higher acetone contents.

The entropy of micelle formation of CTAB in water and acetone-water mixture decreases with the addition of acetone, but for that of SDS, it increases. Further, this type of change implies that the driving force for micellization in water-CTAB-acetone and water-SDS-acetone systems under these conditions must be accredited to the enthalpic term. The similar type of behavior of CTAB and SDS was observed in the presence of co-solvents such as DMSO, DMF, DMA, THF, dioxane and acetonitrile [18-22]. Because the entropy of micellization values of
Table 2 CMC, $a$, $\Delta G_{\mathrm{m}}^{\circ}, \Delta H_{\mathrm{m}}^{\circ}, \Delta S_{\mathrm{m}}^{\circ}$ and $\Delta G_{\text {trans }}^{\mathrm{o}}$ for the CTAB from specific conductance measurements in neat water and acetonewater mixtures containing 0.10 and 0.20 volume fractions of acetone at $298.15,308.15$, 318.15 and $323.15 \mathrm{~K}$

\begin{tabular}{|c|c|c|c|c|c|c|c|}
\hline Temperature (K) & $\begin{array}{l}\text { Volume fraction of } \\
\text { acetone }\end{array}$ & $\mathrm{CMC}[\mathrm{mM}]$ & $a$ & $\begin{array}{l}\Delta \mathrm{G}_{\mathrm{m}}^{\circ} \\
{\left[\mathrm{kJ} \mathrm{mol}^{-1}\right]}\end{array}$ & $\begin{array}{l}\Delta \mathrm{H}_{\mathrm{m}}^{\mathrm{o}} \\
{\left[\mathrm{kJ} \mathrm{mol}^{-1}\right]}\end{array}$ & 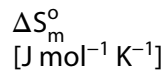 & $\begin{array}{l}\Delta \mathrm{G}_{\text {trans }}^{\mathrm{o}} \\
{\left[\mathrm{kJ} \mathrm{mol}^{-1}\right]}\end{array}$ \\
\hline \multirow[t]{3}{*}{298.15} & 0 & 0.898 & 0.19 & -49.81 & -27.36 & 75.28 & - \\
\hline & 0.1 & 1.50 & 0.20 & -46.57 & -39.74 & 22.92 & 3.24 \\
\hline & 0.2 & 2.00 & 0.21 & -44.66 & -42.54 & 7.12 & 5.15 \\
\hline \multirow[t]{3}{*}{308.15} & 0 & 0.998 & 0.23 & -49.80 & -28.73 & 68.40 & - \\
\hline & 0.1 & 1.91 & 0.24 & -45.99 & -41.46 & 14.68 & 3.81 \\
\hline & 0.2 & 3.30 & 0.25 & -42.87 & -44.30 & -4.65 & 6.93 \\
\hline \multirow[t]{3}{*}{318.15} & 0 & 1.25 & 0.24 & -49.78 & -30.71 & 59.93 & - \\
\hline & 0.1 & 4.86 & 0.25 & -45.92 & -43.82 & 6.59 & 3.86 \\
\hline & 0.2 & 3.90 & 0.26 & -42.85 & -46.94 & -12.84 & 6.93 \\
\hline \multirow[t]{3}{*}{323.15} & 0 & 1.35 & 0.26 & -49.61 & -31.61 & 55.70 & - \\
\hline & 0.1 & 3.18 & 0.27 & -44.95 & -44.76 & 0.596 & 4.66 \\
\hline & 0.2 & 4.38 & 0.28 & -42.82 & -47.89 & -15.68 & 6.79 \\
\hline
\end{tabular}


Table 3 CMC, a

$\Delta \mathrm{G}_{\mathrm{m}}^{\circ}, \Delta \mathrm{H}_{\mathrm{m}^{\prime}}^{\circ} \Delta \mathrm{S}_{\mathrm{m}}^{\circ}$ and $\Delta G_{\text {trans }}^{\circ}$ for the SDS from specific conductance measurements in neat water and acetonewater mixtures containing 0.10 and 0.20 volume fractions of acetone at 298.15, 308.15, 318.15 and $323.15 \mathrm{~K}$

\begin{tabular}{llcccccc}
\hline Temperature (K) & $\begin{array}{l}\text { Volume } \\
\text { fraction of } \\
\text { acetone }\end{array}$ & $\mathrm{CMC}[\mathrm{mM}]$ & $\mathrm{a}$ & $\begin{array}{l}\Delta \mathrm{G}_{\mathrm{m}}^{\circ} \\
{\left[\mathrm{kJ} \mathrm{mol}^{-1}\right]}\end{array}$ & $\begin{array}{l}\Delta \mathrm{H}_{\mathrm{m}}^{\circ} \\
{\left[\mathrm{kJ} \mathrm{mol}^{-1}\right]}\end{array}$ & $\begin{array}{l}\Delta \mathrm{S}_{\mathrm{m}}^{\circ} \\
{\left[\mathrm{mol}^{-1} \mathrm{~K}^{-1}\right]}\end{array}$ & $\begin{array}{l}\Delta \mathrm{G}_{\text {trans }}^{\circ}\left[\mathrm{kJ} \mathrm{mol}^{-1}\right] \\
298.15\end{array}$ \\
\hline 0 & 7.80 & 0.45 & -34.07 & -12.53 & 72.23 & - \\
& 0.1 & 10.3 & 0.64 & -28.69 & -6.41 & 74.72 & 5.38 \\
308.15 & 0.2 & 11.2 & 0.73 & -26.26 & -3.94 & 74.88 & 7.81 \\
& 0 & 8.60 & 0.46 & -34.59 & -13.24 & 69.31 & - \\
318.15 & 0.1 & 10.5 & 0.65 & -29.42 & -6.80 & 73.41 & 5.17 \\
& 0.2 & 11.5 & 0.75 & -26.62 & -3.94 & 73.58 & 7.97 \\
323.15 & 0 & 9.50 & 0.47 & -35.06 & -14.02 & 66.14 & - \\
& 0.1 & 11.30 & 0.66 & -29.81 & -7.16 & 71.19 & 5.17 \\
& 0.2 & 12.00 & 0.78 & -26.67 & -3.71 & 74.52 & 8.39 \\
& 0 & 10.20 & 0.48 & -35.08 & -14.38 & 64.05 & - \\
& 0.1 & 11.9 & 0.67 & -29.86 & -7.32 & 69.76 & 5.22 \\
& 0.2 & 12.3 & 0.79 & -26.78 & -4.23 & 69.77 & 8.30 \\
\hline
\end{tabular}

CTAB decreases with the inclusion of acetone, a rise in the orderliness of the water-CTAB-acetone system takes place as the volume of acetone is raised. This is agreeing with strong interactions, such as $\mathrm{H}$-bonding, between acetone and water, which is a well-established fact. It is noted that acetone forms a clathrate of the stoichiometry $\mathrm{CH}_{3} \mathrm{COCH}_{3} \cdot 17 \mathrm{H}_{2} \mathrm{O}[23,24]$.

The value of $\Delta G_{\text {trans }}^{\circ}$ slowly rises with an increase in the volume fraction of acetone in the water. The plot of $\Delta H_{\mathrm{m}}^{\circ}$ and $\Delta S_{m}^{o}$ values displays the joint correlation phenomena of the enthalpy-entropy compensation. When the enthalpy provides less contribution to $\Delta G_{m^{\prime}}^{o}$ its counterpart noted as $\Delta S_{\mathrm{m}}^{\circ}$ has higher participation in creating free energy to have a large negative value and vice versa.

The linear variation (Figs. 7 and 9) for $\Delta H_{\mathrm{m}}^{\circ}$ with $\Delta S_{\mathrm{m}}^{\circ}$ gives $\mathrm{T}_{\mathrm{c}}$ and another linear variation (Figs. 8 and 10) for $\Delta H_{\mathrm{m}}^{\circ}$ with $\mathrm{T}$ gives $\Delta_{\mathrm{m}} \mathrm{C}_{\mathrm{p}}^{\circ}$. The $\mathrm{T}_{\mathrm{c}}$ values obtained for water, 0.1 and 0.2 volume fractions of acetone measured at $298.15,308.15,318.15$ and $323.15 \mathrm{~K}$, respectively.

The values of $\mathrm{T}_{\mathrm{c}^{\prime}} \sigma$ and $\Delta_{\mathrm{m}} \mathrm{C}_{\mathrm{p}}^{\circ}$ for CTAB and SDS are given in Table 4 for the acetone-water system.
Fig. 7 Plot of $\Delta H_{\mathrm{m}}^{\circ}$ versus $\Delta S_{\mathrm{m}}^{\circ}$ (CTAB)

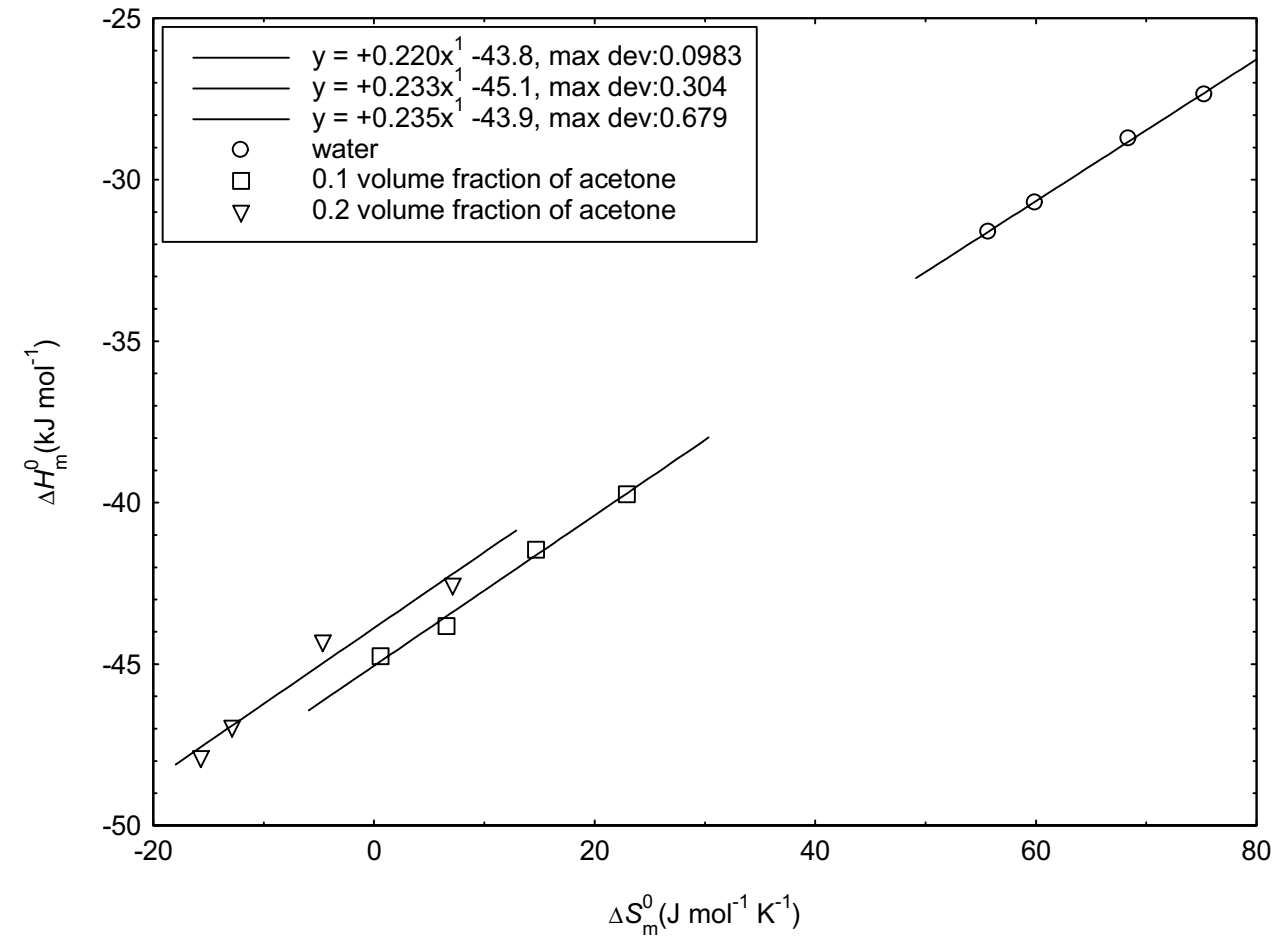


Fig. 8 Plot of $\Delta H_{m}^{o}$ versus $T$ (CTAB)

Fig. 9 Plot of $\Delta \mathrm{H}_{\mathrm{m}}^{\circ}$ versus $\Delta \mathrm{S}_{\mathrm{m}}^{\circ}$ (SDS)

The $\Delta_{m} C_{p}^{o}$ value decreases for neat water, 0.1 and 0.2 volume fraction of acetone.

\subsection{Correlation of $\Delta G_{m}^{\circ}$ with solvent parameters}

We have correlated $\Delta G_{\mathrm{m}}^{\mathrm{o}}$ with dielectric constant $(D)$, viscosity $\left(\eta_{0}\right)$, Reichardt's parameter $\left(E_{\mathrm{T}}\right)[25]$, the
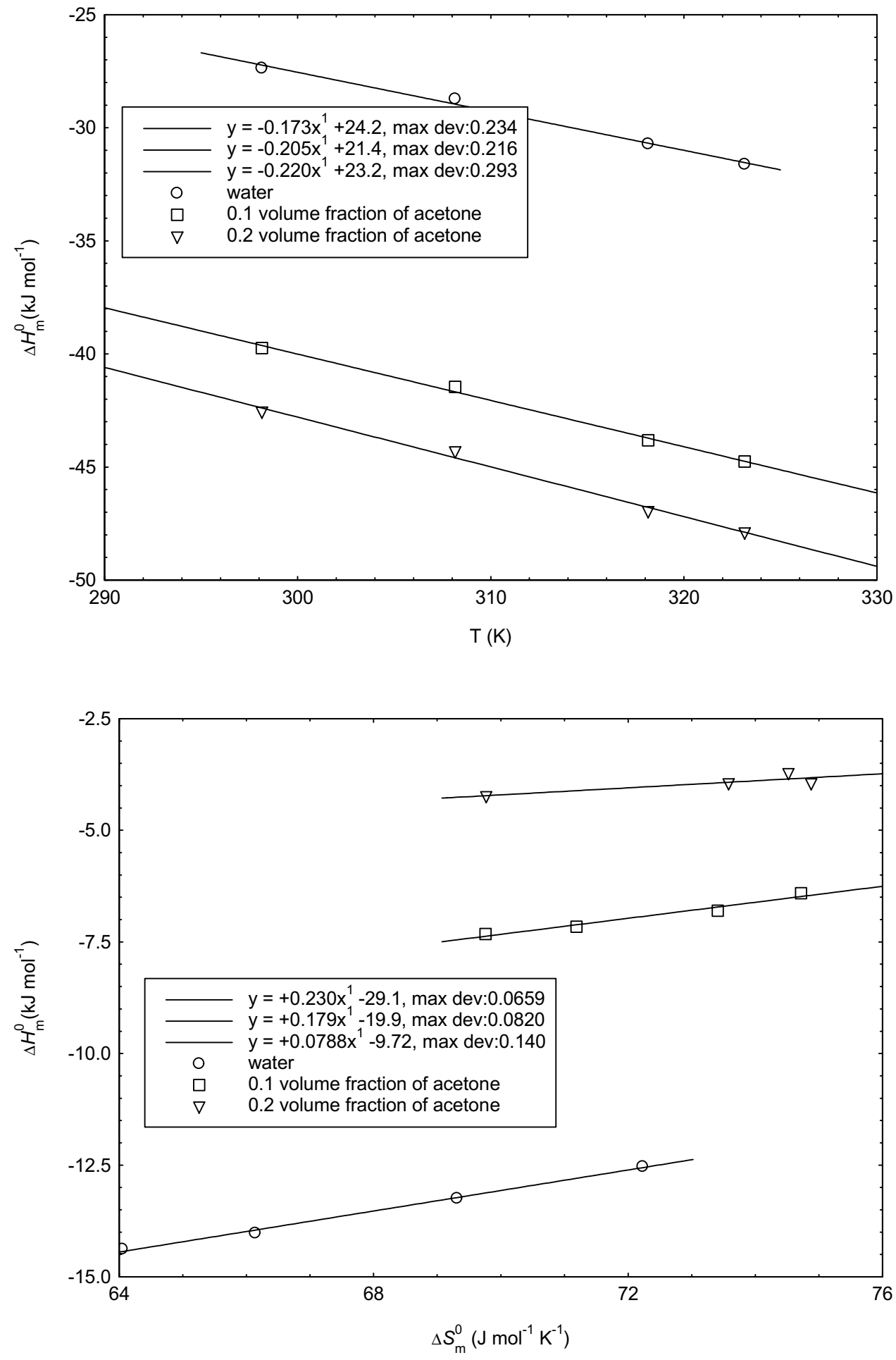

SN Applied Sciences

Hildebrand parameter $(\delta)$ [26-28], and the Gordon parameter $(G)$ [29]. Since aggregation exists of molecular association, the fluidity, polarity and solvent structure are anticipated to impress the process [30]. Here, we used the acetone-water mixture to see the influence of CTAB and SDS on the $\Delta G_{\mathrm{m}}^{\circ}$ values. 
Fig. 10 Plot of $\Delta \mathrm{H}_{\mathrm{m}}^{\circ}$ versus $\mathrm{T}$ (SDS)

Table 4 Values of $\mathrm{T}_{c}, \sigma$ and $\Delta_{\mathrm{m}} C_{\mathrm{p}}^{\circ}$ for CTAB and SDS in the acetone-water mixture

Fig. 11 Plot of $\Delta G_{m}^{0}$ versus 1/D at $298.15 \mathrm{~K}(\mathrm{CTAB})$

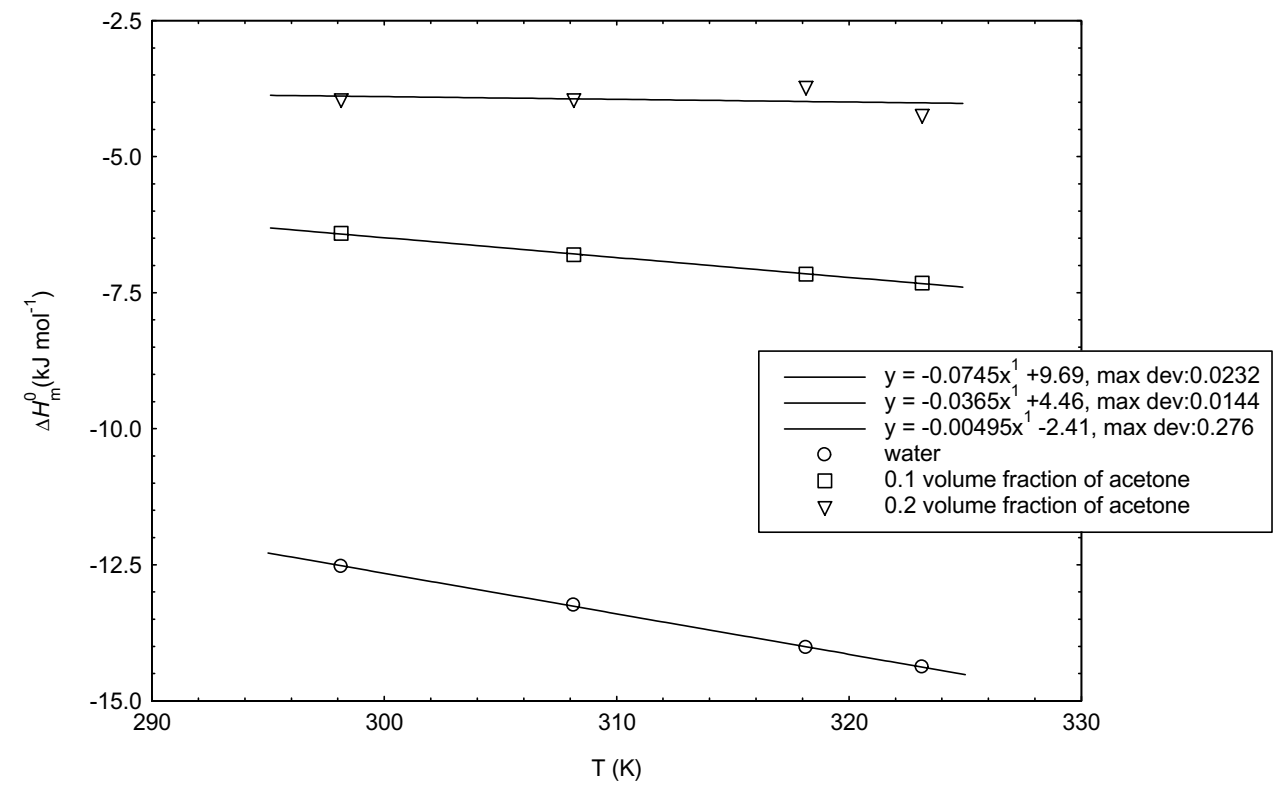

\begin{tabular}{|c|c|c|c|c|c|c|}
\hline \multirow[t]{2}{*}{ Compensation parameters } & \multicolumn{3}{|l|}{ CTAB } & \multicolumn{3}{|l|}{ SDS } \\
\hline & Water & 0.1 acetone & 0.2 acetone & Water & 0.1 acetone & 0.2 acetone \\
\hline $\mathrm{T}_{\mathrm{c}}(\mathrm{K})$ & 4.54 & 4.29 & 4.25 & -0.198 & -0.032 & -0.013 \\
\hline$\sigma$ & -43.8 & -45.1 & -43.9 & 9674.0 & 2789.0 & 9674.0 \\
\hline$\Delta_{\mathbf{m}} C_{\mathbf{P}}^{\mathbf{o}}\left(\mathrm{Jmol}^{-1} \mathrm{~K}^{-1}\right)$ & -173 & -205 & -220 & -74.4 & -31.0 & -5.05 \\
\hline
\end{tabular}


Fig. 12 Plot of $\Delta G_{\mathbf{m}}^{\mathbf{o}}$ versus $\rho$ at 298.15 K(CTAB)

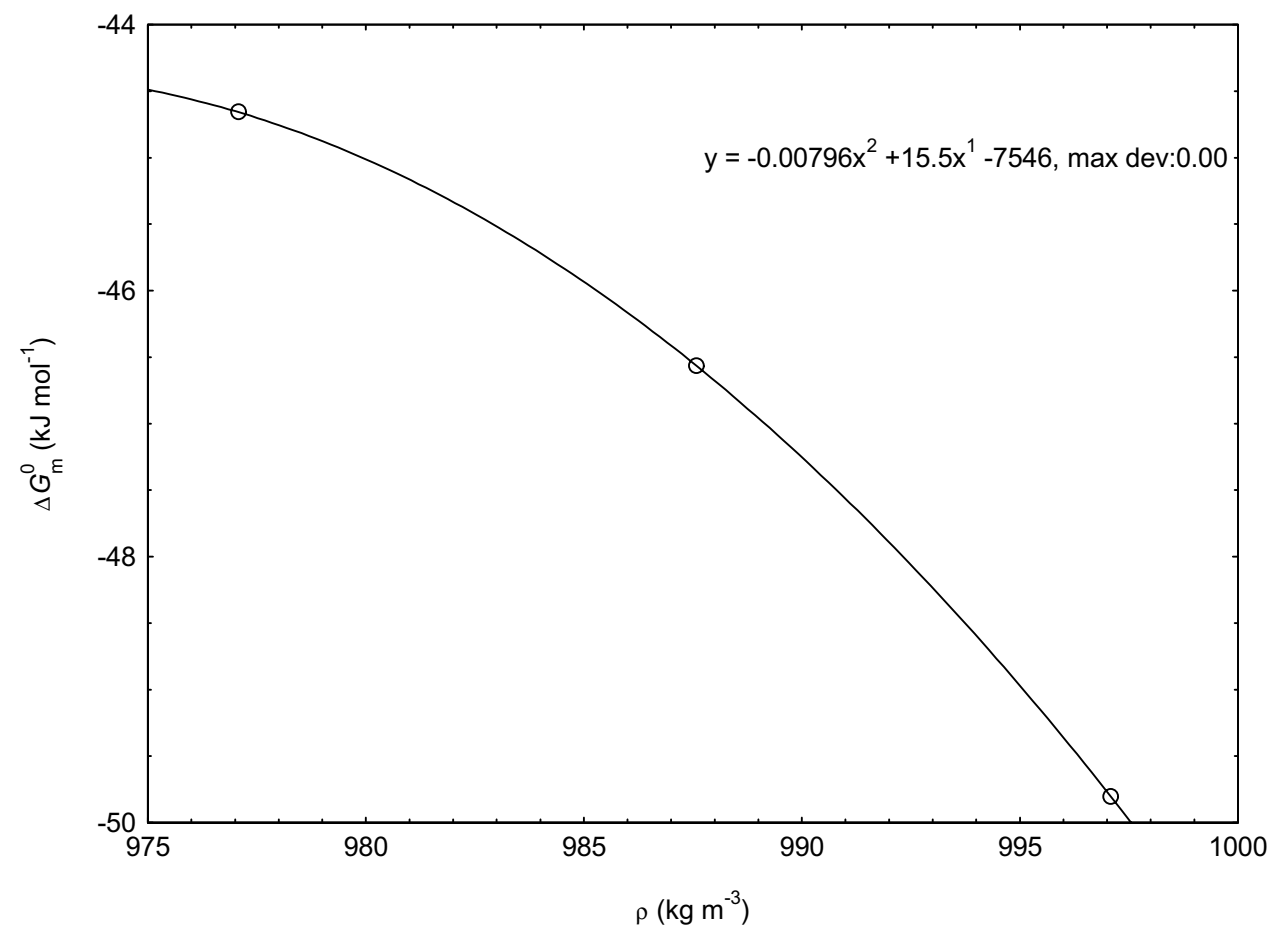

Fig. 13 Plot of $\Delta G_{\mathbf{m}}^{\mathbf{o}}$ versus $\eta_{0}$ at $298.15 \mathrm{~K}(\mathrm{CTAB})$

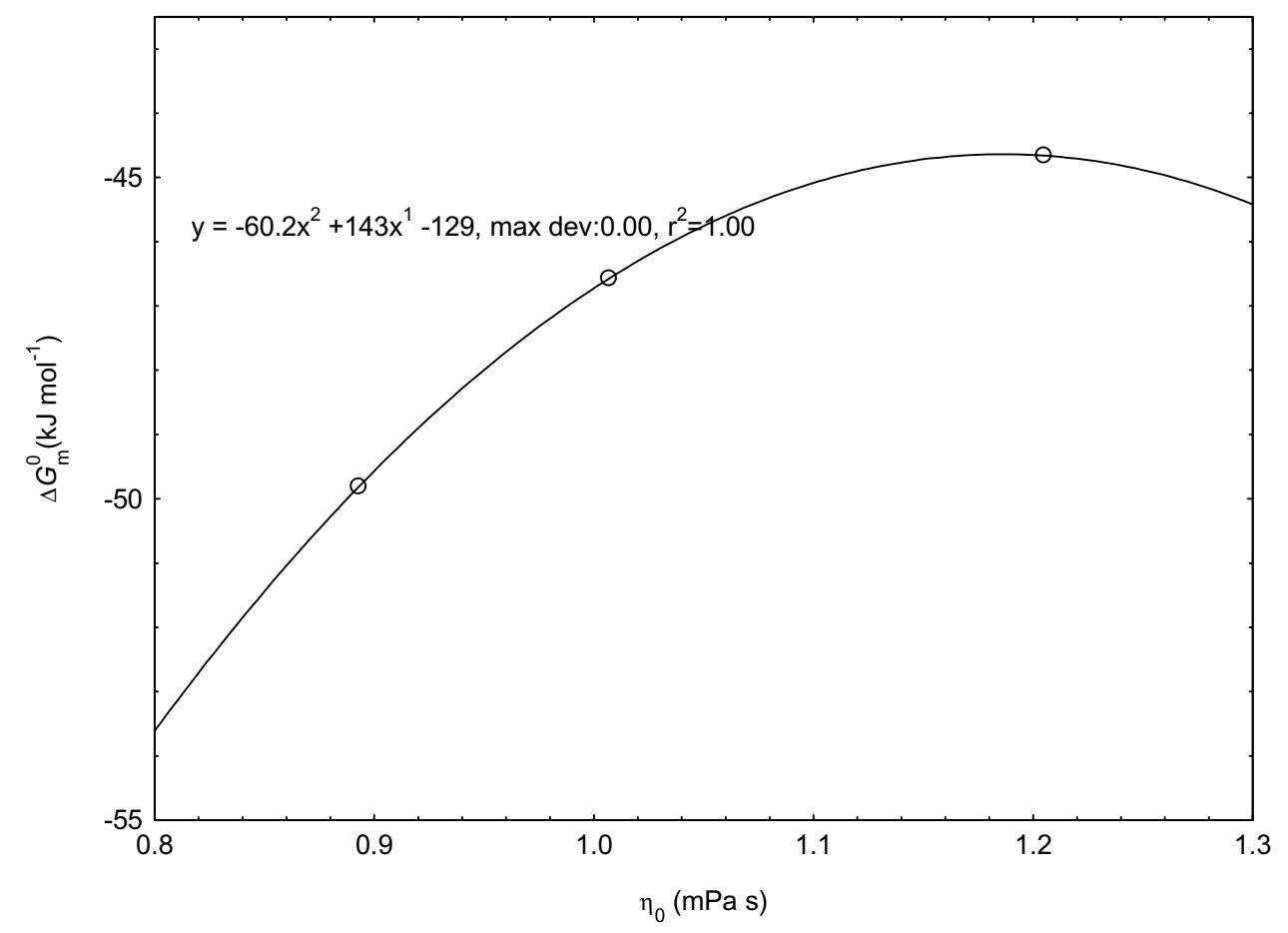

In Figs. $11,12,13,14,15$ and 16 , the dependence of $\Delta G_{\mathbf{m}}^{\mathbf{o}}$ (CTAB) and in Figs. 17, 18, 19, 20, 21 and 22, the dependence of $\Delta G_{\mathbf{m}}^{\mathbf{o}}$ (SDS) on the solvent parameters, $E_{\mathrm{T}}, \eta_{0}, D, G, \rho$ and $\delta$ of the acetone-water mixture are presented. The $E_{T}, \eta_{0}, \rho$ and $D$ were used from the literature [31-37], $G$ values were calculated by us (Table 5 ) and $\delta$ values were evaluated with the empirical relationship given elsewhere $[38,39]$ between $\delta$ and D:

$\delta=0.45 D+18.5$

For $C T A B$ and SDS, the curves were concave down decreasing for the relation of $\Delta G_{\mathrm{m}}^{\circ}$ with $E_{\mathrm{T}}$ and $\delta$, while 
Fig. 14 Plot of $\Delta G_{m}^{\mathbf{o}}$ versus $E_{\mathrm{T}}$ at $298.15 \mathrm{~K}(\mathrm{CTAB})$

Fig. 15 Plot of $\Delta G_{\mathrm{m}}^{0}$ versus $\mathrm{G}$ at $298.15 \mathrm{~K}(\mathrm{CTAB})$
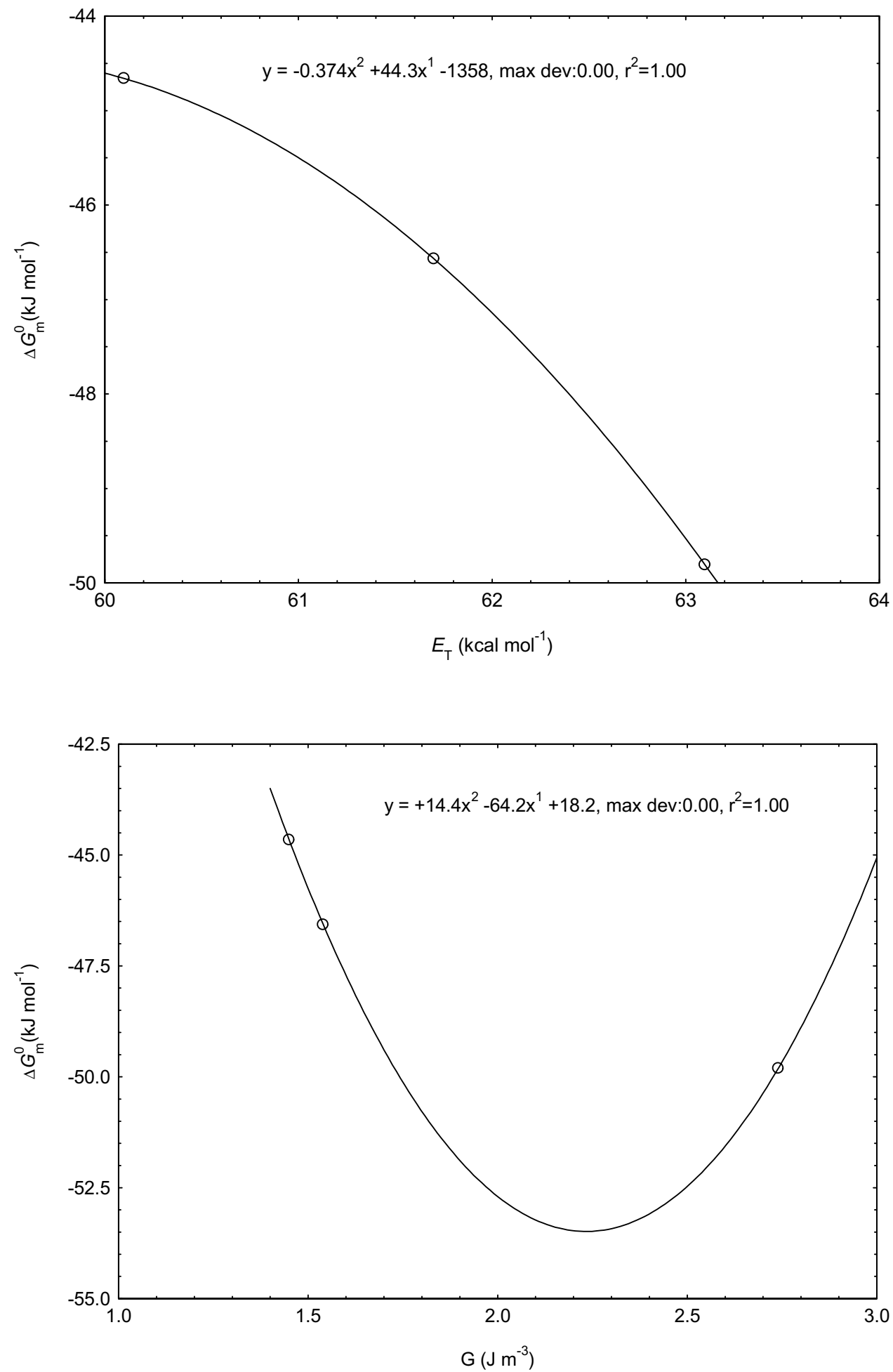

curves were concave down increasing for the relation of $\Delta G_{\mathrm{m}}^{\circ}$ with $D$ and $\eta_{0}$ in the acetone-water mixture. But the relation of $\Delta G_{\mathbf{m}}^{\mathbf{0}}$ with $\rho$ for CTAB is convex while for SDS is concave down decreasing. Even though few chemists $[40,41]$ noticed the linear relationship between $\Delta G_{m}^{\circ}$ and
$G$ for some surfactants in mixed aqua-organic solvents, the points in the graphs were widely scattered for witnessing poor correlations, but the curve for CTAB and SDS in the acetone-water system is convex. 
Fig. 16 Plot of $\Delta G_{\mathrm{m}}^{\mathbf{o}}$ versus $\delta$ at $298.15 \mathrm{~K}$ (CTAB)
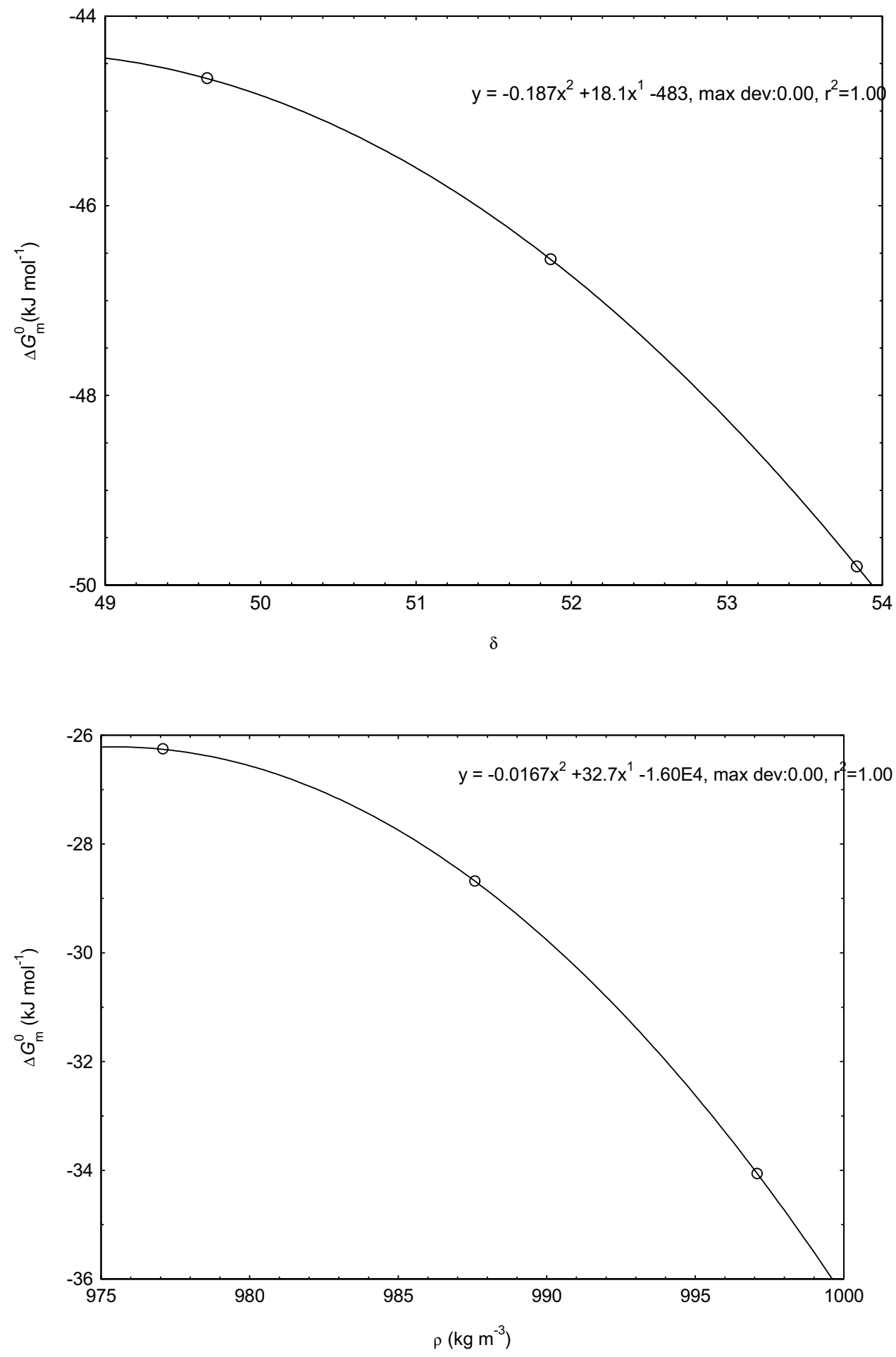

Fig. 17 Plot of $\Delta G_{\mathbf{m}}^{\mathbf{o}}$ versus $\rho$ (SDS)

\subsection{Correlation of $\Delta G_{m}^{o}$ with the Solvophobic Parameter}

From the theory of solute-solvent interactions, the interaction of alkyl chains with solvents can be marked by the solvophobicity of hydrocarbons [42]. The solvophobic power of hydrocarbons can be explained by their solvophobic parameter, $\mathrm{Sp}$, calculated by the Gibbs energies of transfer of hydrocarbons from the gas into a given solvent [42]. 
Fig. 18 Plot of $\Delta G_{\mathrm{m}}^{\mathbf{o}}$ versus $1 / D$ (SDS)

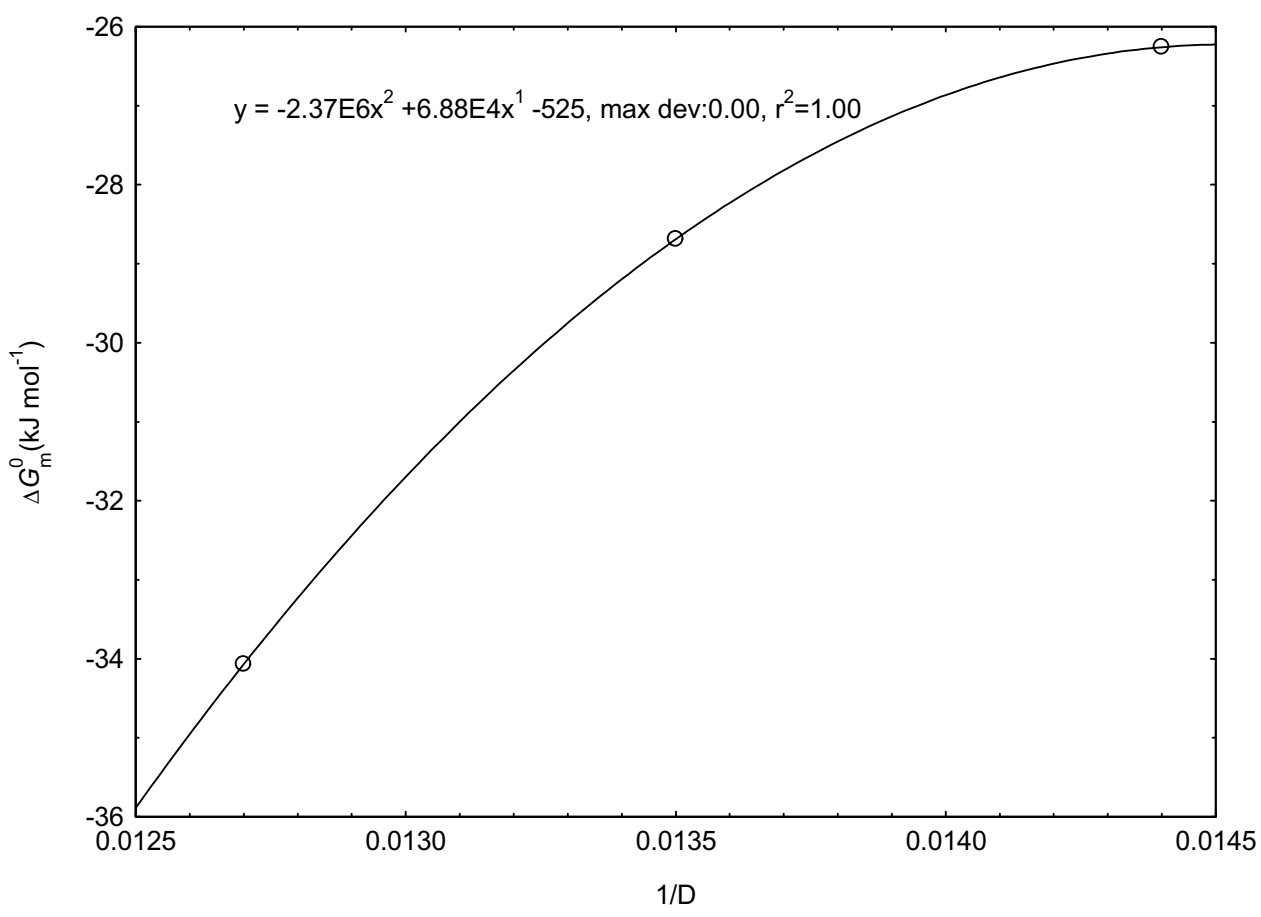

Fig. 19 Plot of $\Delta G_{\mathbf{m}}^{\mathbf{o}}$ versus $\eta_{0}$ (SDS)

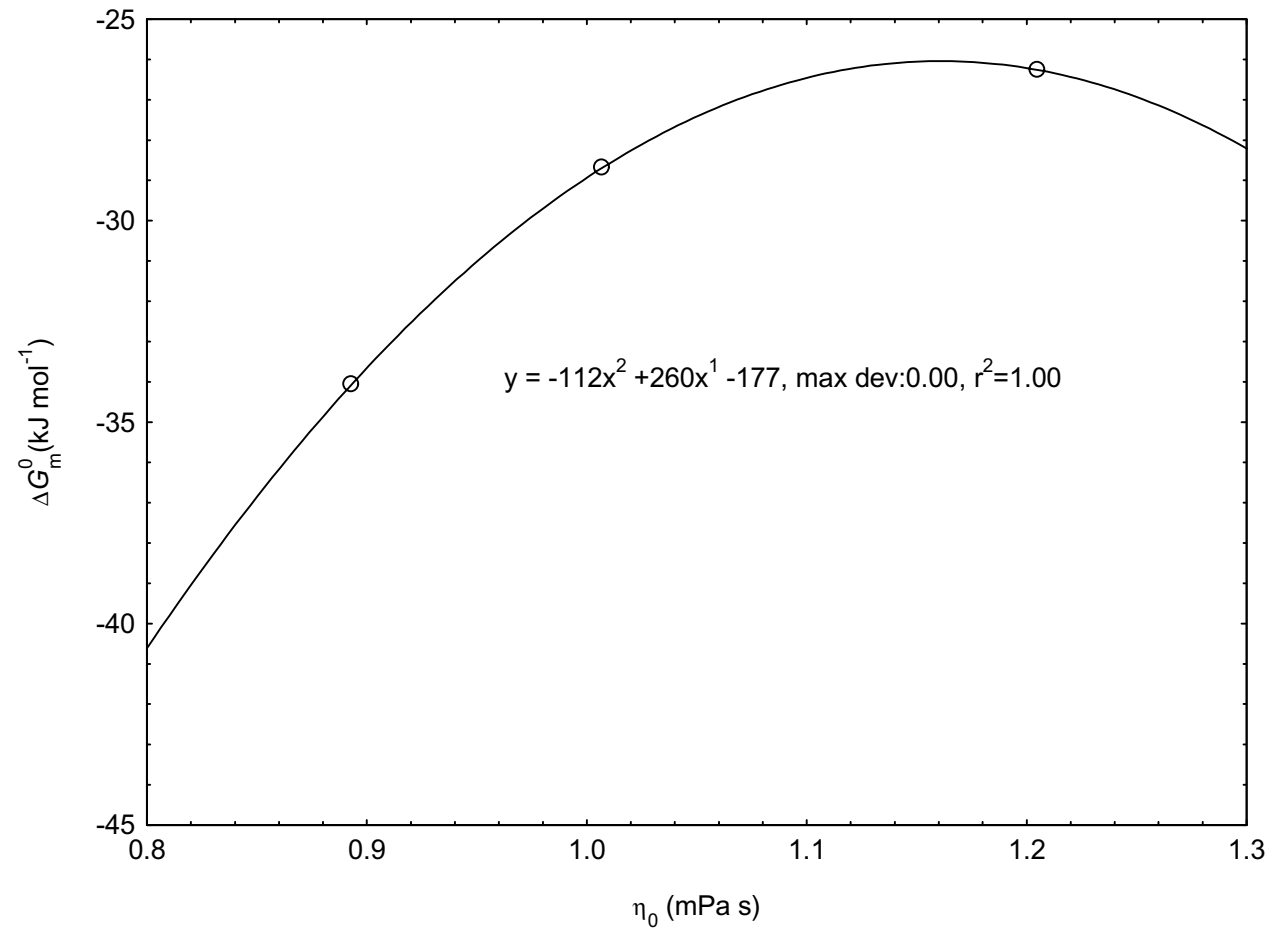

It can be seen from Figs. 23 and 24 that the $\Delta G_{\mathrm{m}}^{\mathbf{o}}$ values decrease with increasing $S_{\mathrm{p}}$ values in the acetone-water mixture. This indicates that the $\Delta G_{\mathbf{m}}^{\mathbf{o}}$ values depend strongly on the solvophobic power of hydrocarbons in water-acetone mixtures.

\subsection{Contact angles}

Surfactants play an important role in the wetting of lowenergy solid surfaces, and the contact angle can successfully reflect the wetting ability. For a perfect, homogeneous solid surface, the great plan of the force balance 
Fig. 20 Plot of $\Delta G_{\mathrm{m}}^{\mathbf{o}}$ versus $\delta$ (SDS)
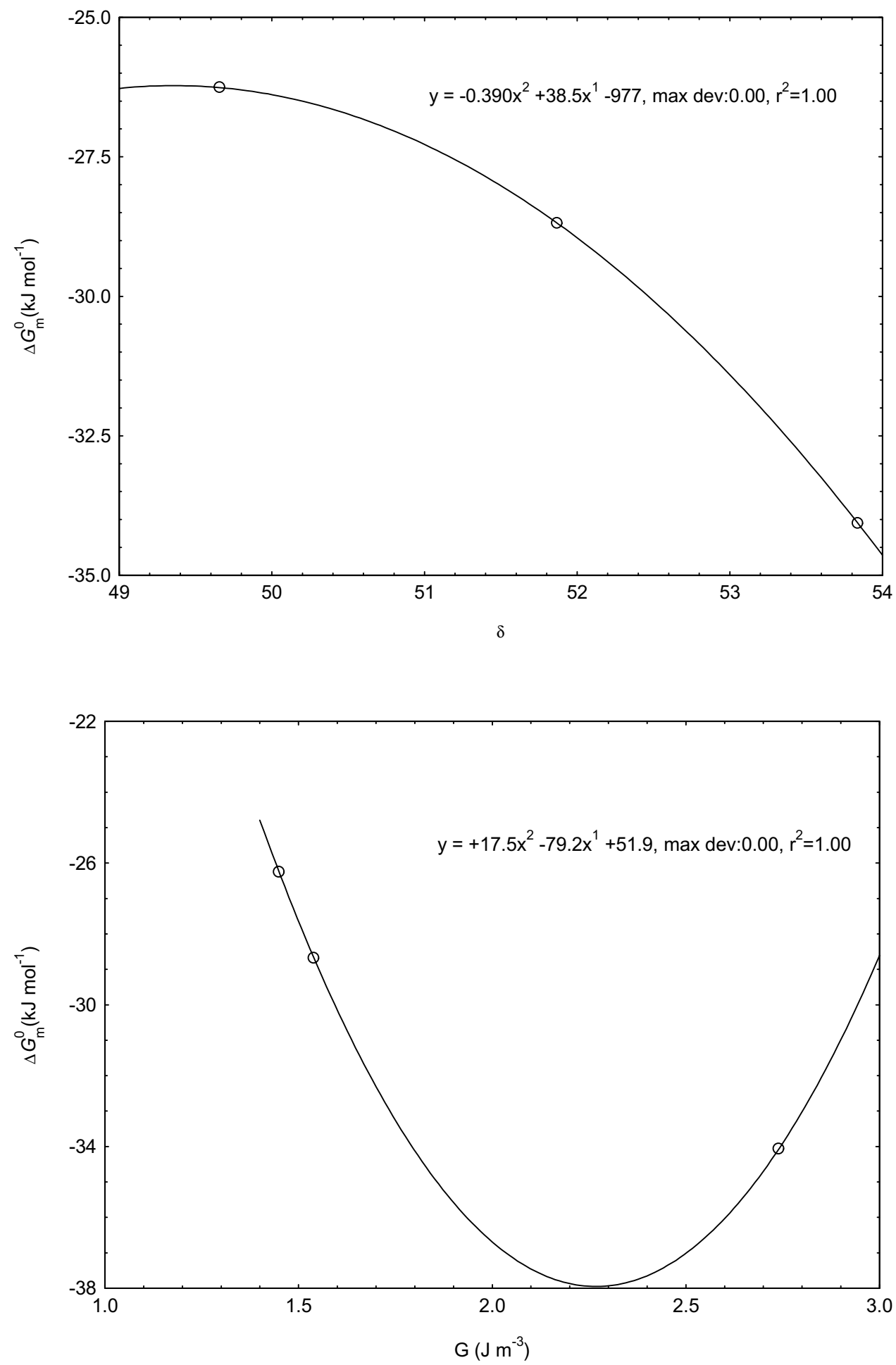

Fig. 21 Plot of $\Delta G_{\mathrm{m}}^{\mathrm{o}}$ versus $\mathrm{G}$ (SDS) on the contact line predicts the contact angle $(\theta)$ with respect to the interfacial energy densities of the three interfaces of the system [43]. The Young-Dupre condition [Eq. (8)] depicts this equalization. It can be determined by limiting the mechanical energy of the system for different varieties of the contact zones of the solid, fluid, and vapor stages [44-46].

$$
\cos \theta=\frac{\left(\gamma_{s g}-\gamma_{s l}\right)}{\gamma_{l g}}
$$

The Young-Dupre equation speaks to the association of the tiny contact angle to the interfacial tensions acting on the contact line and emerging from the molecular and 
Fig. 22 Plot of $\Delta G_{m}^{o}$ versus $E_{T}$ (SDS)

Table 5 Various

Physicochemical parameters of the mixed solvents (acetonewater) at $298.15 \mathrm{~K}$

Fig. 23 Plot of $\Delta G_{\mathrm{m}}^{0}$ versus $\mathrm{S}_{\mathrm{P}}$ (CTAB)

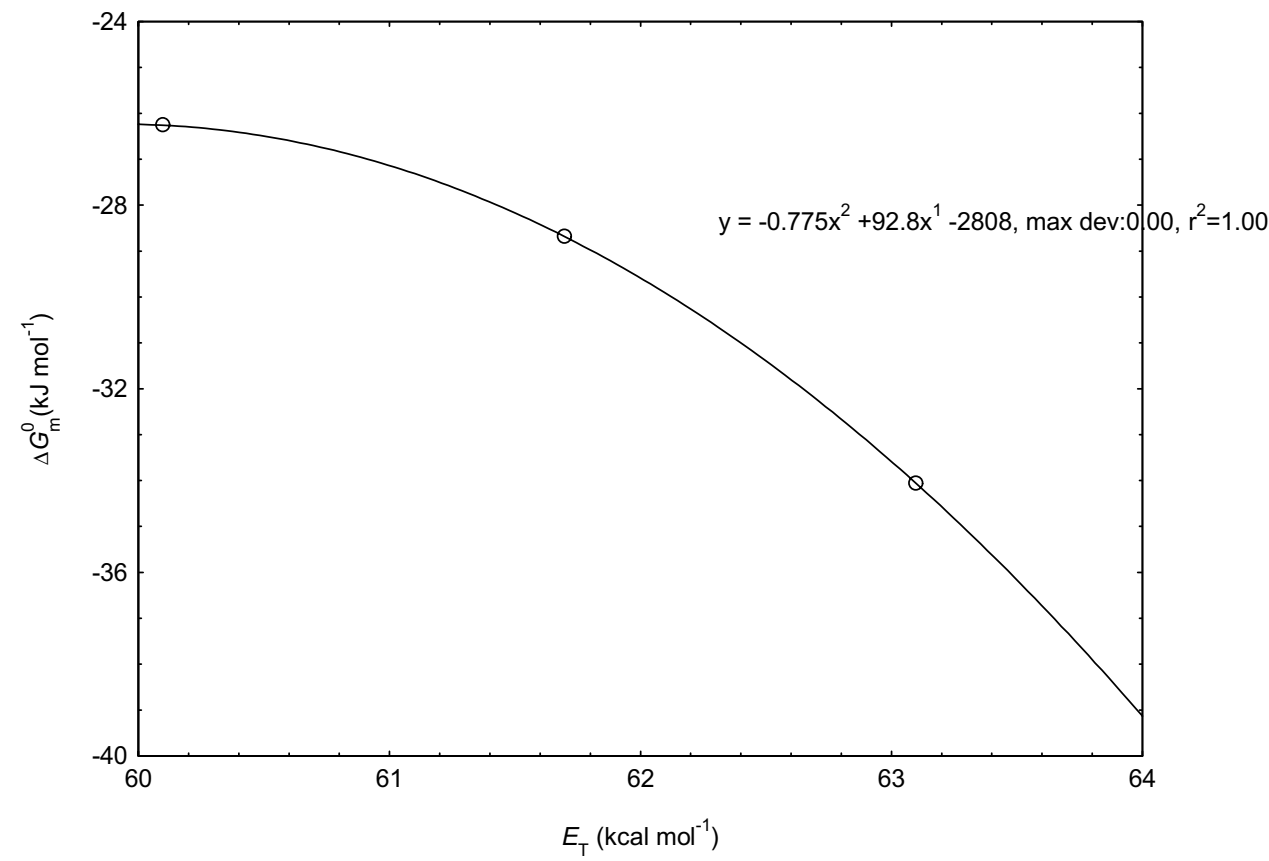

\begin{tabular}{llllllll}
\hline $\begin{array}{l}\text { Volume fraction } \\
\text { of acetone }\end{array}$ & $1 / \mathrm{D}$ & $\eta_{\mathrm{o}}(\mathrm{mPa} \mathrm{s})$ & $E_{\mathrm{T}}\left(\mathrm{kcal} \mathrm{mol}^{-1}\right)$ & $G\left(\mathrm{~J} \mathrm{~m}^{-3)}\right.$ & $\rho\left(\mathrm{kg} \mathrm{m}^{-3}\right)$ & $\delta$ & $S_{\mathrm{P}}$ \\
\hline 0 & 0.0127 & 0.893 & 63.10 & 2.740 & 997.100 & 53.84 & 1.00 \\
0.1 & 0.0135 & 1.007 & 61.66 & 1.537 & 987.582 & 51.87 & 0.919 \\
0.2 & 0.0144 & 1.205 & 60.15 & 1.450 & 977.136 & 49.66 & 0.818 \\
\hline
\end{tabular}

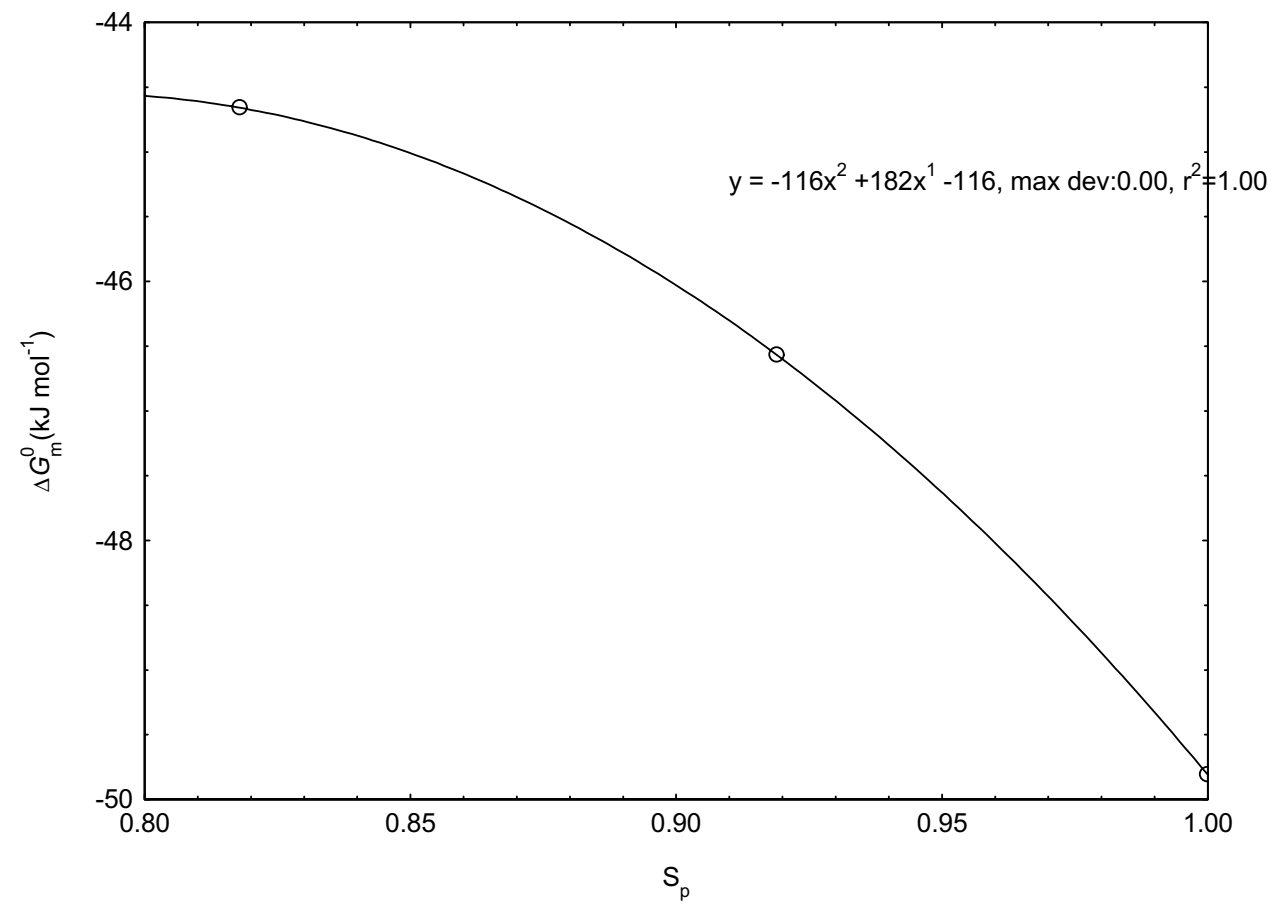


Fig. 24 Plot of $\Delta G_{\mathrm{m}}^{\mathrm{o}}$ versus $\mathrm{S}_{\mathrm{p}}$ (SDS)

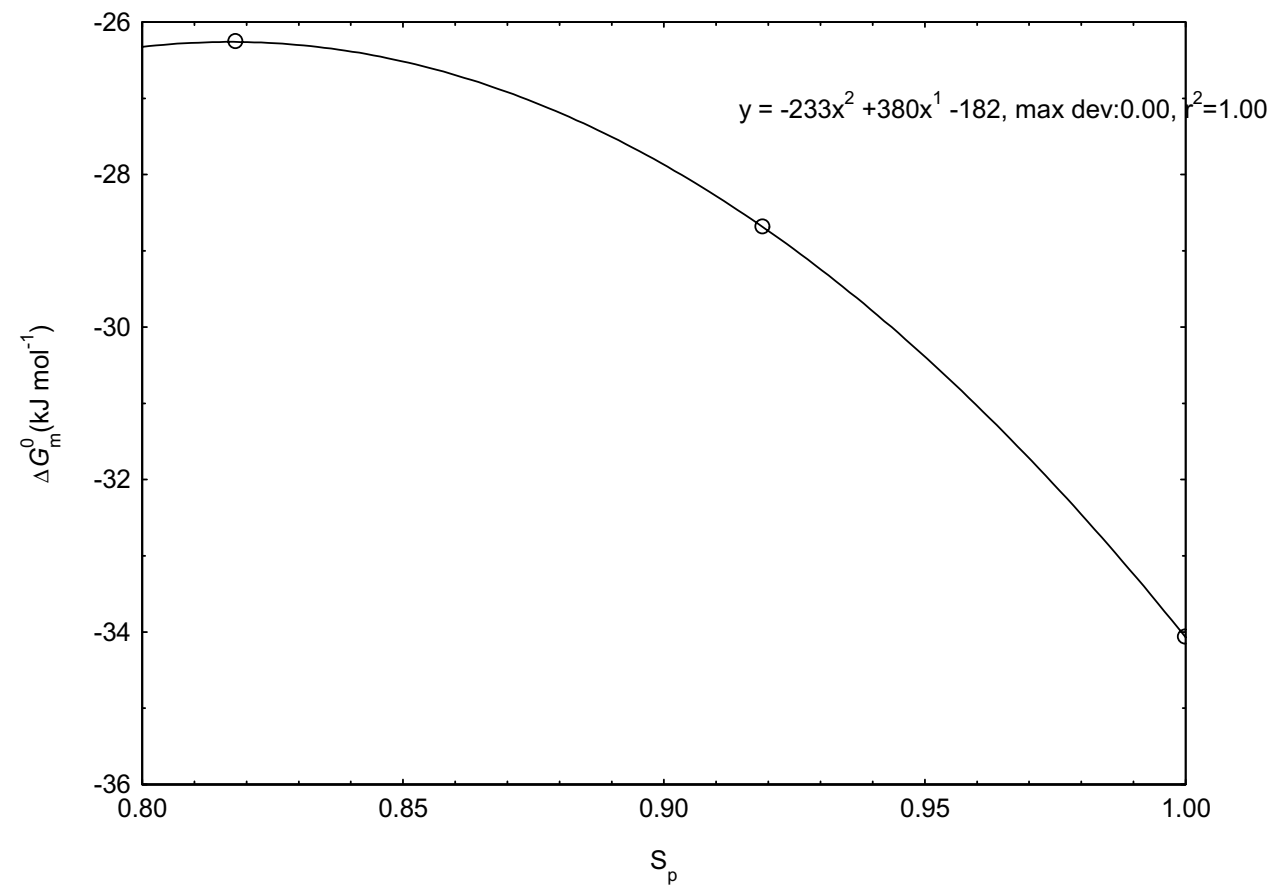

infinitesimal structure and science of the interfaces. Here, $\theta$ is the contact angle, $\gamma_{s g}, \gamma_{l g}$ and $\gamma_{s l}$ are the surface tensions at the interfaces of solid/gas, liquid/gas and solid/liquid, respectively.

Starkweather et al. [47] made two solutions of oil/SDS in water, one is below CMC ( $8 \mathrm{mM})$ and another is above CMC $(20 \mathrm{mM})$ to study the change in contact angle on stainless steel and optical glass surfaces, and they observed that increasing the surfactant concentration causes a decrease in the oil/surfactant solution interfacial tension for solutions of SDS resulted in a decrease in the change in the contact angle, but $20 \mathrm{mM}$ SDS did not yield an optimum but only a decrease in the change in the contact angle as the $\mathrm{pH}$ increased.
Fig. 25 Plot of contact angle versus $\log C$ (CTAB)

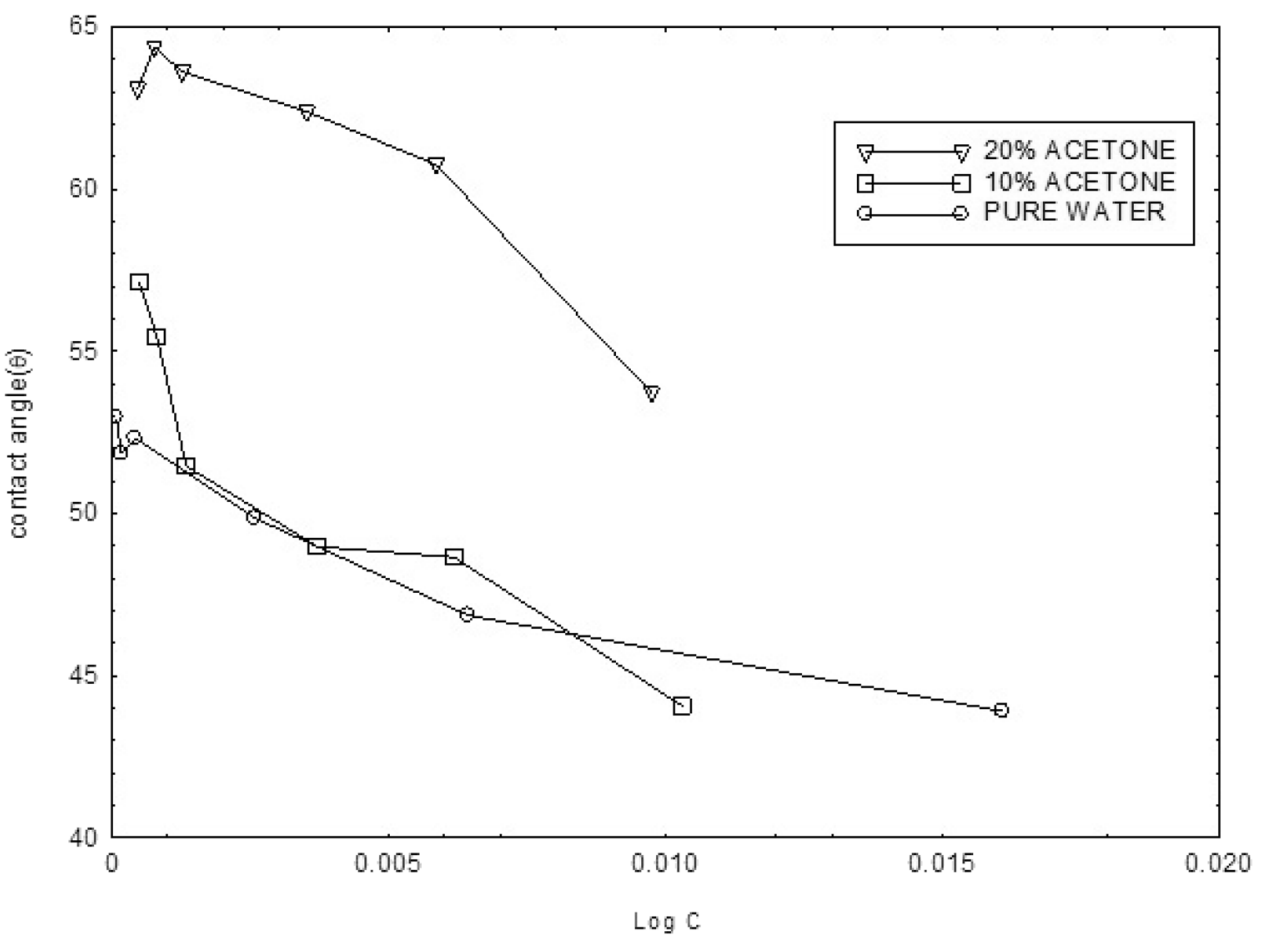


Fig. 26 Plot of contact angle versus Log C (SDS)

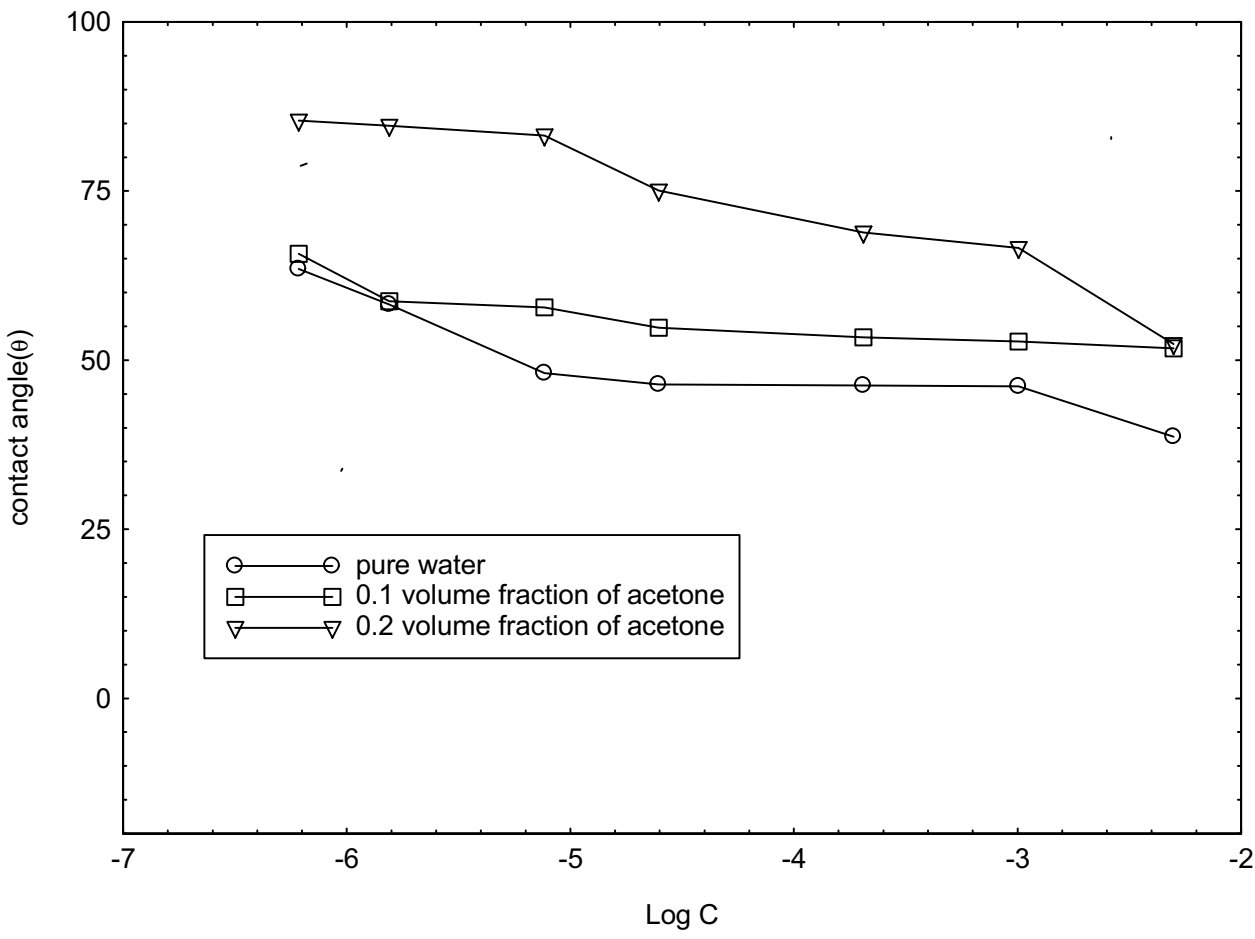

In this study, the contact angle and surface free energy of CTAB and SDS in acetone-water mixed solvent media (containing water, 0.10 and 0.20 volume fractions of acetone) were measured on the Borosilicate glass surface and aluminum surface respectively at $298.15 \mathrm{~K}$. Based on Figs. 25 and 26, the CA increases with decreases in the concentration of CTAB and SDS for different volumes fraction of acetone. Similar results were observed by Menezes et al. [37].

\section{Conclusion}

The exploratory outcomes for the conductance of CTAB and SDS in pure water and acetone-water mixtures have been introduced as a component of surfactant concentration.

The conductance was observed increase with increasing surfactant concentration while values were likewise observed to be diminished with an increase in acetone content in the mixed solvent media. The values of the preCMC slope $\left(\mathrm{S}_{1}\right)$ and post-CMC slope $\left(\mathrm{S}_{2}\right)$ gives an appropriate view in regards to the solution nature of $C T A B$ and SDS. The CMC and a were observed to increase for both $C T A B$ and SDS up to 0.20 volume fraction of acetone. After 0.20 volume fraction, no CMC was observed. The free energies and enthalpy of micelle development were observed to be negative for both $C T A B$ and DTAB but enthalpy goes on decreasing with increasing volume fraction of acetone for CTAB in a given mixed-solvent media which is contrary to the enthalpy of micellization for SDS with increasing the volume fraction of acetone. The entropy of micellization increases for SDS whereas decreases for CTAB with the increase in the volume fraction of acetone. It can be seen that $\Delta G_{\mathbf{m}}^{\mathbf{o}}$ values in the acetone-water mixture do not show a straight forward linear correlation with the different studied solvent parameters i.e. $D, E_{\mathrm{T}}, G, \eta_{0}, \rho$ and $\delta$. The standard free energy of micellization values decrease with increasing $S_{p}$ values in the acetone-water mixtures indicating strongly dependent on the solvophobic power of hydrocarbons in water-acetone mixtures.

Also, the contact angles increased with a decrease in the concentration of CTAB and SDS in pure water, 0.10 and 0.20 volume fraction of acetone for different concentrations.

Acknowledgements The authors are thankful to the World Academy of Sciences (TWAS) for providing M.Sc. fellowships and funds to purchase the Drop Shape Analyzers (DSA 25E) from KRUSS, Germany through the 17-533 RG/CHE/AS_G/TWAS Research Grants, Italy.

\section{Compliance with ethical standards}

Conflict of interest The authors declare that they have no conflict of interest. 


\section{References}

1. Marques EF, Silva BFB (2013) Surfactant self-assembly. In:Tadros $\mathrm{T}$ (ed) Encyclopedia of Colloid and Interface Science. Springer, Berlin, pp 1202-1241

2. Tanford C (1991) The hydrophobic effect: formation of Micelles and Biological membranes. Krieger, Malabar

3. Mata J, Varade D, Bahadur P (2005) Aggregation behavior of quaternary salt based cationic surfactants. Thermochim Acta 428:147-155

4. Miyagishi S (1974) The effect of organic additives on the micelle formation of dodecylammonium halides in aqueous solutions. Bull Chem Soc Jpn 47:2972-2976

5. Miyagishi S (1975) The micelle formation of alkylammonium chloride in 1-propanol-water and acetone-water mixtures. Bull Chem Soc Jpn 48:2349-2352

6. Miyagishi S (1976) The effect of organic additives on the thermodynamic parameters of micellization. Bull Chem Soc Jpn 49:34-37

7. Treiner C, Le Besnerais A (1977) Standard free energy of transfer of ionic surfactants from water to water + acetone mixtures from vapour pressure measurements. J Chem Soc Faraday Trans 1 Phys Chem Condens Phases 73:44

8. Ionescu LG, De Fávere VT (1982) Formation of micelles of cetyltrimethylammonium bromide in water-acetone solutions. In: Mittal KL, Fendler EJ (eds) Solution behavior of surfactants. Springer, Boston, pp 407-416

9. Yadav CD, Bhattarai A (2014) A comparative study of conductance of sodium dodecyl sulphate in different percentage of ethanol water media at 308.15 K. J Nepal Chem Soc 33:51-56

10. Bhattarai A, Chatterjee SK, Niraula TP (2013) Effects of concentration, temperature and solvent composition on density and apparent molar volume of the binary mixtures of cationicanionic surfactants in methanol-water mixed solvent media. SpringerPlus. https://doi.org/10.1186/2193-1801-2-280

11. Cookey GA, Obunwo CC, Uzoma DO (2015) The effect of temperature on the micellization of an anionic surfactant in mixed solvent systems. J Appl Chem 8(12):49-54

12. Malliaris A, Binana W (1984) Micellization of sodium dodecyl sulfate in water-acetone mixed solutions. J Colloid Interface Sci 102:305-307

13. Kim H-U, Lim K-H (2004) A model on the temperature dependence of critical micelle concentration. Colloids Surf A Physicochem Eng Asp 235:121-128

14. Di Michele A, Brinchi L, Di Profio P, Germani R, Savelli G, Onori $G$ (2011) Effect of head group size, temperature and counterion specificity on cationic micelles. J Colloid Interface Sci 358:160-166

15. Kabir-ud-Din, Rub MA, Naqvi AZ (2011) Self-association behavior of amitriptyline hydrochloride as a function of temperature and additive (inorganic salts and ureas) concentration. Colloids Surfaces B Biointerfaces 82:87-94

16. Carnero Ruiz C (1999) Thermodynamics of micellization of tetradecyltrimethylammonium bromide in ethylene glycol-water binary mixtures. Colloid Polym Sci 277:701-707

17. Zana R (1996) Critical micellization concentration of surfactants in aqueous solution and free energy of micellization. Langmuir 12:1208-1211

18. Ionescu LG, Tokuhiro T, Czerniawski BJ, Smith ES (1979) Formation of micelles of cetyltrimethylammonium bromide in water-dimethyl sulfoxide solutions. In: Mittal KL (ed) Solution chemistry of surfactants. Springer, New York, pp 487-496

19. Tokuhiro T, Ionescu LG (1979) Temperature effect on molecular dynamics in micellar system. Proton spin-lattice relaxation study of cetyltrimethylammmonium bromide in water-dimethylsulfoxide mixtures. In: Mittal KL (ed) Solution chemistry of surfactants. Springer, New York, pp 497-506

20. Tokuhiro T, lonescu LG, Fung DS (1979) Effect of intermolecular interactions on the formation of micelles. Proton spin-lattice relaxation study in water + dimethyl sulphoxide solutions of hexadecyltrimethylammonium bromide. J Chem Soc, Faraday Trans 2(75):975-984

21. Fung DS (1978) Molecular interactions in solutions of surfactants and micelles. Doctoral Dissertation

22. Blandamer MJ (1977) Kinetics of organic reactions in water and aqueous mixtures. In: Gold V (ed) Advances in physical organic chemistry. Elsevier, Amsterdam, pp 203-352

23. Franks $F$ (1979) Water-a comprehensive treatise, vol 1-6. Plenum Press, New York

24. Khanzada AWK, Mcdowell CA (1971) Nuclear magnetic resonance study of molecular motion in the clathrate hydrates of cyclopropane and acetone. J Mol Struct 7:241-251

25. Fuoss RM, Kraus CA (1933) Properties of electrolytic solutions. IV. The conductance minimum and the formation of triple ions due to the action of coulomb forces1. J Am Chem Soc 55:2387-2399

26. Hildebrand JH, Scott RL (1964) Solubility of non-electrolytes, 3rd edn. Reinhold, New York

27. Paruta AN, Sciarrone BJ, Lordi NG (1962) Correlation between solubility parameters and dielectric constants. J Pharm Sci 51:704-705

28. Lordi NG, Sciarrone BJ, Ambrosio TJ, Paruta AN (1964) Dielectric constants and solubility. J Pharm Sci 53:463-464

29. Sjoeberg M, Henriksson U, Waernheim T (1990) Deuteron nuclear magnetic relaxation of $[1,1-2 \mathrm{H}]$ hexadecyltrimethylammonium bromide in micellar solutions of nonaqueous polar solvents and their mixtures with water. Langmuir 6:1205-1211

30. Pan A, Naskar B, Prameela GKS, Kumar BVNP, Mandal AB, Bhattacharya SC, Moulik SP (2012) Amphiphile behavior in mixed solvent media I: self-aggregation and ion association of sodium dodecylsulfate in 1,4-dioxane-water and methanol-water media. Langmuir 28:13830-13843

31. Noda K, Ohashi M, Ishida K (1982) Viscosities and densities at 298.15 K for mixtures of methanol, acetone, and water. J Chem Eng Data 27:326-328

32. Quinlan JE, Amis ES (1955) The alkaline hydrolysis of methyl propionate in acetone-water mixtures and solutions of different ionic strength1. J Am Chem Soc 77:4187-4191

33. Sharma V, Cantero-López P, Yañez-Osses O, Kumar A (2018) Effect of cosolvents DMSO and glycerol on the self-assembly behavior of SDBS and CPC: an experimental and theoretical approach. J Chem Eng Data 63:3083-3096

34. Ajmal Koya P, Kabir-ud-Din Ismail K (2012) Micellization and thermodynamic parameters of butanediyl-1,4-bis(tetradecyl dimethylammonium bromide) gemini surfactant at different temperatures: effect of the addition of 2-methoxyethanol. J Solut Chem 41:1271-1281

35. Marcus Y (1994) The use of chemical probes for the characterization of solvent mixtures. Part 2. Aqueous mixtures. J Chem Soc Perkin Trans 2:1751

36. Wang J, Zhang L, Wang H, Wu C (2011) Aggregation behavior modulation of 1-dodecyl-3-methylimidazolium bromide by organic solvents in aqueous solution. J Phys Chem B 115:4955-4962

37. Menezes JL, Yan J, Sharma MM (1989) The mechanism of alteration of macroscopic contact angles by the adsorption of surfactants. Colloids Surf 38:365-390

38. Das C, Das B (2009) Thermodynamic and interfacial adsorption studies on the micellar solutions of alkyltrimethylammonium bromides in ethylene glycol (1) + water (2) mixed solvent media. J Chem Eng Data 54:559-565 
39. Kabir-ud-Din, Ajmal Koya P (2010) Effects of solvent media and temperature on the self-aggregation of cationic dimeric surfactant 14-6-14, 2Br-studied by conductometric and fluorescence techniques. Langmuir 26:7905-7914

40. Tanford C (1980) The hydrophobic effect-formation of micelles and biological membranes, 2nd edn. Wiley, New York

41. Nishikido N, Moroi Y, Uehara H, Matuura R (1974) Effect of alcohols on the micelle formation of nonionic surfactants in aqueous solutions. Bull Chem Soc Jpn 47:2634-2638

42. Marcus Y (1985) Ion solvation. Wiley-Interscience, Chichester

43. Adamson AW (1982) Physical chemistry of surfaces, chapters 10 and 13, 4th edn. Wiley, New York

44. Joshi YP (1990) Shape of a liquid surface in contact with a solid. Eur J Phys 11:125-129
45. Schwartz LW, Garoff S (1985) Contact angle hysteresis and the shape of the three-phase line. J Colloid Interface Sci 106:422-437

46. Eick J, Good R, Neumann A (1975) Thermodynamics of contact angles. II. Rough solid surfaces. J Colloid Interface Sci $53: 235-248$

47. Starkweather BA, Zhang X, Counce RM (2000) An experimental study of the change in the contact angle of an oil on a solid surface. Ind Eng Chem Res 39:362-366

Publisher's Note Springer Nature remains neutral with regard to jurisdictional claims in published maps and institutional affiliations. 